\title{
様相概念に基づく意思決定方式とそのファジィ 多目的線形計画問題への応用
}

\author{
大阪府立大学 乾 口雅 弘 \\ 市橋 秀 友 \\ 田中英 夫
}

（受理 1986 年11月25日；再受理 1987 年3月 28日）

和文概要 本研究では, まずPradeにより提案された可能性測度, 必然性測度, 不可能性測度, 偶然 性測度の 4 つの様相測度について, 様相論理に抢ける相対的可能性の概念を用いて, 相対的な様相測 度と，それに双対な様相測度を定義する。また，乙れらの性質と，通常の 4 つの様相測度との関係に ついて論じる。次に, 起こりうる結果の可能性分布が与えられている意思決定問題に扔いて, てれら の様相測度を用いた決定方式を考察し，分類する。さらに，乙れらの決定方式の応用として，ファジ ィパラメータを含むファジィ多目的線形計画問題を定式化する。乙の問題は非線形計画問題に帰着さ れるが, 常に凸計画問題になるとは限らない。そてで, 大域的最適解の近似解を求めるための解法を 示す。

\section{1.はじめに}

ファジィ理論の研究分野に, 可能性理論〔 1 ] と呼ばれるあのがある。ファジィ集合のメンバシップ 関数を可能性分布と解釈し, ファジィ集合の要素に対するメンバシップ值を可能性の度合と考えるも のである。

てのような可能性分布によって定義されたファジィ測度〔 2 〕が，可能性測度である。可能性測度は， 確率分布のあとでの確率測度に対応するあのであり, 確率的設定のきつい制限をゆるめて, 主観的な 不確実性を表現しようとするあのである。

一方, 数理論理学には, 命題の強弱を扱う様相論理がある。様相論理では “Aである”という命題 以外に“Aでありうる”すなわち，“Aであることが可能である”という命題や，“必ずAである” すなわち, “Aであるととが必然である”という命題なども取り扱われている。このような可能, 必 然などの様相は，アリストテレスらによって考えられてきた。

また, 様相的意味論から, 可能性, 必然性, 不可能性打よび偶然性の測度が, Prade〔3〕により, 提案されている。乙れらの測度は, すべて可能性測度から構成できる。

しかし, これらの様相測度は絶対的な指標であり, 状態 Aである可能性が大きいからといって, 状 態Aでない可能性が小さいとはいえない。 
本論文では，可能性，必然性，不可能性抢よび偶然性の測度から，相対的な様相測度および，それ と双対な測度を定義し，それらの性質を述べる。次に，これらの様相測度を意思決定問題に応用し， 様相的な決定方式について考察する。最後に, これらの決定方式の応用として, 係数が可能性分布と して表されたファジィ多目的線形計画問題を定式化する。乙の問題は非線形計画問題に帰着されるが, 常に凸計画問題になるとは限らない。そこで, 大域的最適解の近似解を求めるための解法を示す。

\section{2. ファジィ集合の樣相測度}

集合 $\mathrm{A}$ の要素が集合 Bに属する度合を, 様相的意味論から, 測度として表現したものを様相測度と 呼ぶ。

Prade [ 3 ]に上る可能性測度 (P O S ), 必然性測度 (NES)，不可能性測度（I MP)，偶然 性測度（CONT）は，次のように表される。

(1) $\operatorname{POS}(\widetilde{\mathrm{B}} / \widetilde{\mathrm{A}})=\sup _{y}\left\{\mu_{\widetilde{\mathrm{A}}}(y) \wedge \mu_{\widetilde{\mathrm{B}}}(y)\right\}$

(2) $\operatorname{NES}(\widetilde{\mathrm{B}} / \widetilde{\mathrm{A}})=\inf _{y}\left\{\left(1-\mu_{\mathrm{A}}(y)\right) \vee \mu_{\widetilde{\mathrm{B}}}(y)\right\}$

(3) $\operatorname{IMP}(\widetilde{\mathrm{B}} / \widetilde{\mathrm{A}})=\inf _{y}\left\{\left(1-\mu_{\widetilde{\mathrm{A}}}(y)\right) \vee\left(1-\mu_{\widetilde{\mathrm{B}}}(y)\right)\right\}$

(4) $\operatorname{CONT}(\widetilde{\mathrm{B}} / \widetilde{\mathrm{A}})=\sup _{y}\left\{\mu_{\widetilde{\mathrm{A}}}(y) \wedge\left(1-\mu_{\widetilde{\mathrm{B}}}(y)\right)\right\}$

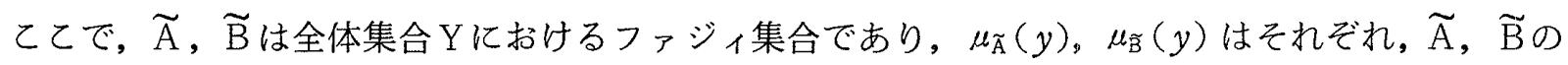

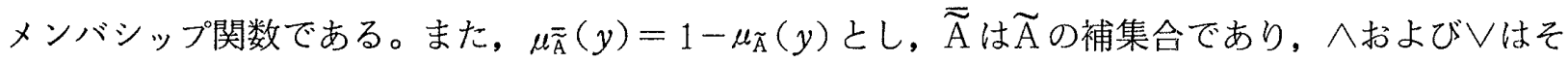
れぞれ, min, maxを示す。

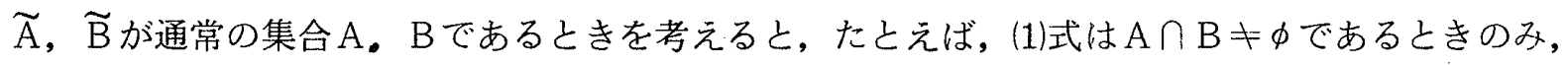
$\mathrm{POS}(\mathrm{B} / \mathrm{A})=1$ となり, 集合 $\mathrm{A}$ の要素が集合Bに属することが可能であるととを示しているてと がわかる。

ファジィ集合 $\widetilde{A} ， \widetilde{B}$ が与えられたときのPOS ( $\widetilde{B} / \widetilde{A}), N E S(\widetilde{B} / \widetilde{A}), I M P(\widetilde{B} / \widetilde{A}), \operatorname{CONT}$ $(\widetilde{\mathrm{B}} / \widetilde{\mathrm{A}})$ を図示すると, 図1のようになる。

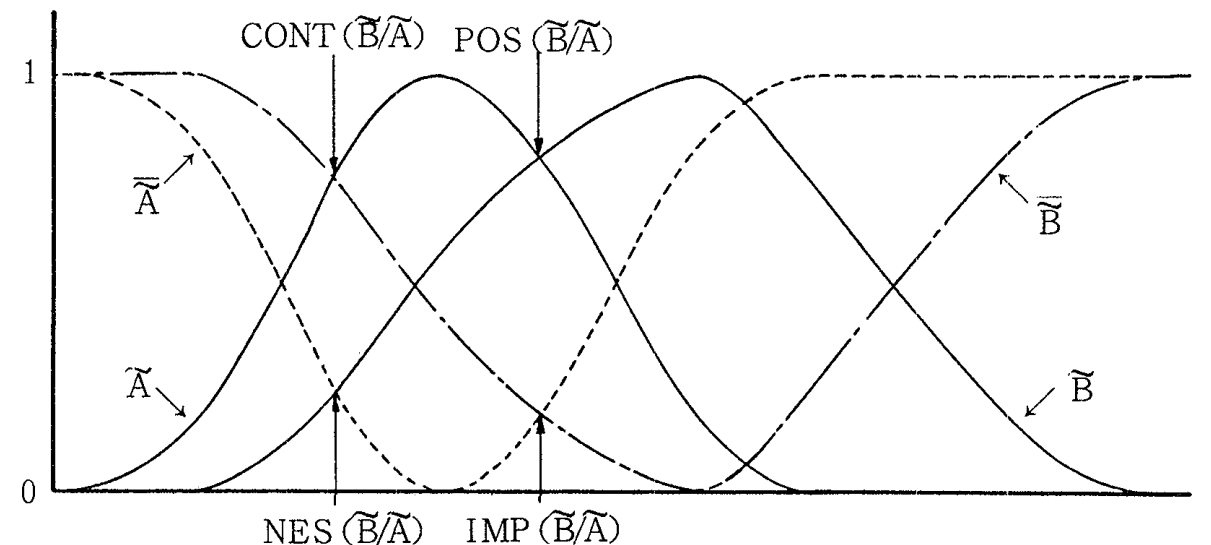

図 $1 \operatorname{POS}(\widetilde{B} / \widetilde{A}), \operatorname{NES}(\widetilde{B} / \widetilde{A}), I M P(\widetilde{B} / \widetilde{A}), \operatorname{CONT}(\widetilde{B} / \widetilde{A})$ 
可能性測度，必然性測度，不可能性測度，偶然性測度には，次の等式が成立する。

(5) $\operatorname{IMP}(\widetilde{\mathrm{B}} / \widetilde{\mathrm{A}})=1-\operatorname{POS}(\widetilde{\mathrm{B}} / \widetilde{\mathrm{A}})$

(6) $\operatorname{CONT}(\widetilde{\mathrm{B}} / \widetilde{\mathrm{A}})=\operatorname{POS}(\widetilde{\mathrm{B}} / \widetilde{\mathrm{A}})$

(7) $\operatorname{NES}(\widetilde{B} / \widetilde{A})=1-\operatorname{POS}(\widetilde{\mathrm{B}} / \widetilde{\mathrm{A}})$

(8) $\operatorname{POS}(\widetilde{\mathrm{B}} / \widetilde{\mathrm{A}})=\operatorname{POS}(\widetilde{\mathrm{A}} / \widetilde{\mathrm{B}})$

(9) $\operatorname{IMP}(\widetilde{\mathrm{B}} / \widetilde{\mathrm{A}})=\operatorname{IMP}(\widetilde{\mathrm{A}} / \widetilde{\mathrm{B}})$

(10) $\operatorname{NES}(\widetilde{B} / \widetilde{A})=\operatorname{NES}(\widetilde{\widetilde{A}} / \widetilde{B})$

(11) $\operatorname{CONT}(\widetilde{\mathrm{B}} / \widetilde{\mathrm{A}})=\operatorname{CONT}(\overline{\widetilde{\mathrm{A}}} / \widetilde{\mathrm{B}})$

また， $\widetilde{A}$ 正規なファジィ集合とし， $\widetilde{\mathrm{A}}_{1} \subseteq \widetilde{\mathrm{A}}_{2}, \widetilde{\mathrm{B}}_{1} \subseteq \widetilde{\mathrm{B}}_{2}$ とすると，次の不等式が成立する。

(12) $\operatorname{POS}\left(\widetilde{B}_{1} / \widetilde{A}\right) \geqq N E S\left(\widetilde{B_{1}} / \widetilde{A}\right)$

(13) $\operatorname{POS}\left(\widetilde{B}_{1} / \widetilde{\mathrm{A}}_{1}\right) \leqq \operatorname{POS}\left(\widetilde{B}_{2} / \widetilde{\mathrm{A}}_{1}\right)$

(14) $\operatorname{POS}\left(\widetilde{\mathrm{B}}_{1} / \widetilde{\mathrm{A}}_{1}\right) \leqq \operatorname{POS}\left(\widetilde{\mathrm{B}}_{1} / \widetilde{\mathrm{A}}_{2}\right)$

(15) $\quad \mathrm{NES}\left(\widetilde{\mathrm{B}}_{1} / \widetilde{\mathrm{A}}_{1}\right) \leqq \mathrm{NES}\left(\widetilde{\mathrm{B}}_{2} / \widetilde{\mathrm{A}}_{1}\right)$

(16) $\operatorname{NES}\left(\widetilde{\mathrm{B}}_{1} / \widetilde{\mathrm{A}}_{1}\right) \geqq \mathrm{NES}\left(\widetilde{\mathrm{B}}_{1} / \widetilde{\mathrm{A}}_{2}\right)$

ただし，正規なファジィ集合 $\widetilde{A}$ と， $\mu_{\tilde{A}}(y)=1$ となる $y$ が存在するファジィ集合のととであり，フ ァジィ集合の包含関係 $\widetilde{\mathrm{A}}_{1} \subseteq \widetilde{\mathrm{A}}_{2}$ は，それぞれのメンバシップ関数 $\mu_{\widetilde{\mathrm{A}}_{1}}, \mu_{\widetilde{\mathrm{A}}_{2}}$ を用いて, $\mu_{\mathrm{A}_{1}}(y) \leqq \mu_{\mathrm{A}_{2}}(y)$ と定義される。

(12)式〜(16)式において，POSをIMP，NESをCONTに置き換え，不等号の向きを逆にしても， 不等式は成立する。

さらに, $\widetilde{A}_{i}, \widetilde{B}_{i}$ を全体集合 $Y_{i}$ のアジィ集合とする。てのとき, 直積集合 $\prod_{i=1}^{n} Y_{i}$ 上での可能性測度 は, 次のように, 各全体集合 $Y_{i}$ 上での可能性測度に分解して考えられることが示されている〔3][4]。 ただし，ファジィ集合 $\widetilde{\mathrm{A}}_{1}, \widetilde{\mathrm{A}}_{2}$ の直積 $\widetilde{\mathrm{A}}_{1} \times \widetilde{\mathrm{A}}_{2}$ は, $\quad \mu_{\mathbb{A}_{1} \times \widetilde{\mathrm{A}}_{2}}\left(y_{1}, y_{2}\right)=\min \left[\mu_{\widetilde{\mathrm{A}}_{1}}\left(y_{1}\right), \mu_{\widetilde{\mathrm{A}}_{2}}\left(y_{2}\right)\right]$ で定 義されるあのとする。

(17) $\operatorname{POS}\left(\prod_{i=1}^{\mathrm{n}} \widetilde{B}_{i} / \prod_{i=1}^{n} \widetilde{A}_{i}\right)=\bigwedge_{i=1}^{n} \operatorname{POS}\left(\widetilde{B}_{i} / \widetilde{A}_{i}\right)$

特に, $\widetilde{\mathrm{A}}_{\mathrm{i}}$ が正規なファジィ集合であるとき，必然性測度についてあ次式が成立する〔3〕〔4〕。

(18) $\quad \operatorname{EES}\left(\prod_{i=1}^{\mathrm{n}} \widetilde{B}_{i} / \prod_{i=1}^{n} \widetilde{A}_{i}\right)=\hat{\bigwedge}_{i=1}^{n} \operatorname{NES}\left(\widetilde{B}_{i} / \widetilde{A}_{i}\right)$

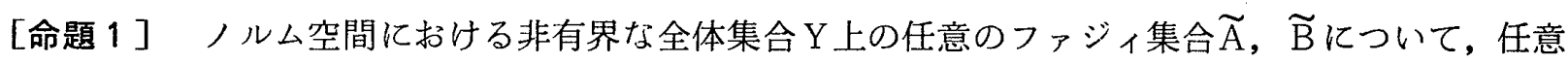
の $h \in[0,1) k$ 対し, $(\widetilde{\mathrm{A}})_{h}=\left\{y / \mu_{\tilde{\mathrm{A}}}(y)>h\right\}$ が非有界となり任意の $h \in(0,1]$ 亿対し, $[\widetilde{\mathrm{B}}]_{h}$ $=\left\{y / \mu_{\widetilde{\mathrm{B}}}(y) \geqq h\right\}$ が有界となるならば,

(19) $\operatorname{NES}(\widetilde{\mathrm{B}} / \widetilde{\mathrm{A}})=0$

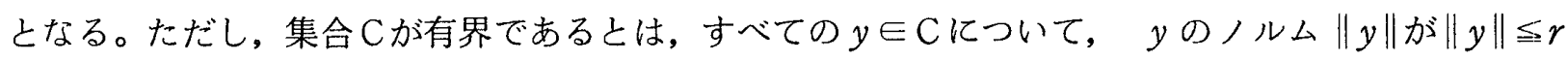
となる有限の $r か ゙$ 存在することである。 
（証明） $(\widetilde{\mathrm{A}})_{h},[\widetilde{\mathrm{B}}]_{h}$ の特性関数をそれぞれ， $\chi_{(\widetilde{\mathrm{A}})_{h}}(y), \chi_{[\widetilde{\mathrm{B}}]_{h}}(y)$ とする。まず，

$$
\left(1-\mu_{\AA}(y)\right) \vee \mu_{\mathbb{B}}(y)=\inf _{h \in(0,1]}\left[h \vee\left\{\left(1-\chi(\tilde{\AA})_{1-h}(y)\right) \vee \chi_{[\tilde{\mathbb{B}}]_{h}}(y)\right\}\right]
$$

を示す。

Yの任意の要素 $y$ について, $\left(1-\mu_{\tilde{\AA}}(y)\right) \vee \mu_{\tilde{B}}(y)=h_{1}$ とすると, 任意の $h \in\left(0, h_{1}\right]$ にいて, $\left(1-\mu_{\tilde{\mathrm{A}}}(y)\right) \vee \mu_{\tilde{\mathrm{B}}}(y) \geq h$ となる。したがって， $\mu_{\widetilde{\mathrm{B}}}(y) \geq h$ または， $\mu_{\tilde{\mathrm{A}}}(y) \leqq 1-h$ が成立する。す

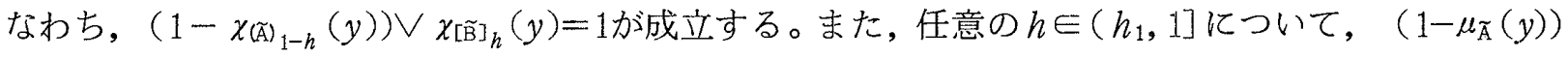
$\vee \mu_{\tilde{\mathrm{B}}}(y)<h$ となる。したがって，的 $(y)<h$ かつ， $\mu_{\tilde{\mathrm{A}}}(y)>1-h$ が成立する。すなわち， $\left(1-\chi(\tilde{A})_{1-h}(y)\right) \vee \chi_{[\tilde{\mathrm{B}}]_{h}}(y)=0$ が成立する。ゆえに,

$$
\begin{aligned}
& \inf _{h \in(0,1]}\left[h \vee\left\{\left(1-\chi_{(\tilde{\mathrm{A}})_{1-h}}(y)\right) \vee \chi_{[\tilde{\mathrm{B}}]_{h}}(y)\right\}\right]=\inf _{h \in\left(0, h_{1}\right]}\left[h \vee\left\{\left(1-\chi_{(\tilde{\mathrm{A}})_{1-h}}(y)\right) \vee \chi_{[\tilde{\mathrm{B}}]_{h}}(y)\right\}\right] \\
& \widehat{\wedge} \inf _{h \in\left(h_{1}, 1\right]}\left[h \vee\left\{\left(1-\chi_{(\widetilde{A})_{1-h}}(y)\right) \vee \chi_{[\tilde{\mathrm{B}}]_{h}}(y)\right\}\right] \\
& =\inf _{h \in\left(0, h_{1}\right]}[h \vee 1] \bigwedge_{h \in\left\{h_{1}, 1\right]}[h \vee 0] \\
& =h_{1}
\end{aligned}
$$

つまり，

$$
\left(1-\mu_{\tilde{\mathrm{A}}}(y)\right) \vee \mu_{\widetilde{\mathrm{B}}}(y)=\inf _{h \in[0,1]}\left[h \vee\left\{\left(1-\chi_{(\tilde{A})_{1-h}}(y)\right) \vee \chi_{[\tilde{\mathrm{B}}]_{h}}(y)\right\}\right]
$$

が成立する。

このととにより，

$$
\begin{aligned}
\operatorname{NES}(\widetilde{\mathrm{B}} / \widetilde{\mathrm{A}}) & =\inf _{y} f\left\{\left(1-\mu_{\widetilde{\mathrm{A}}}(y)\right) \vee \mu_{\widetilde{\mathrm{B}}}(y)\right\} \\
& =\inf _{y} \inf _{h \in(0,1]}\left[h \vee\left\{\left(1-\chi_{(\widetilde{\mathrm{A}})_{1-h}}(y)\right) \vee \chi_{[\widetilde{\mathrm{B}}]_{h}}(y)\right\}\right] \\
& =\inf _{h \in(0,1]}\left[h \vee \inf _{y}\left\{\left(1-\chi_{(\widetilde{\mathrm{A}})_{1-h}}(y)\right) \vee \chi_{[\widetilde{\mathrm{B}}]_{h}}(y)\right\}\right]
\end{aligned}
$$

と書ける。

いま，任意に $h \in(0,1]$ をとると，仮定により $[\widetilde{\mathrm{B}}]_{h}$ は有界であり，( $\left.\widetilde{\mathrm{A}}\right)_{1-h}$ は非有界であるから， $\chi_{[\widetilde{\mathrm{B}}]_{h}}(y)=0$ かつ $\chi_{(\widetilde{\mathrm{A}})_{1-h}}(y)=1$ となる $y$ が存在する。したがって，

$$
h \vee \inf _{y}\left\{\left(1-\chi_{(\tilde{A})}{ }_{1-h}(y)\right) \vee \chi_{[\tilde{\mathrm{B}}]}(y)\right\}=h
$$

となる。 $h$ は $(0,1]$ の範囲で任意であったから，

$\mathrm{NES}(\widetilde{\mathrm{B}} / \widetilde{\mathrm{A}})=\inf _{h \in(0,1]} h=0$

となる。

（証明終り） 
こてで, 新たな様相測度として，相対的可能性測度を定義する。

[定義1]ファジィ集合 $\widetilde{\mathrm{A}}$ の要素が $\widetilde{\mathrm{B}}$ に属する可能性が， $\widetilde{\mathrm{B}}$ に属さない可能性よりも大きい度合を相対 的可能性測度（RP）と呼び，次のように定義する。

(21) $\operatorname{RP}(\widetilde{\mathrm{B}} / \widetilde{\mathrm{A}}) \triangleq \max [\operatorname{POS}(\widetilde{\mathrm{B}} / \widetilde{\mathrm{A}})-\operatorname{POS}(\widetilde{\mathrm{B}} / \widetilde{\mathrm{A}}), 0]$

$$
\begin{aligned}
& =\max [\operatorname{POS}(\widetilde{B} / \widetilde{A})+\operatorname{NES}(\widetilde{B} / \widetilde{A})-1,0] \\
& =\operatorname{POS}(\widetilde{B} / \widetilde{A}) \otimes \operatorname{NES}(\widetilde{B} / \widetilde{A})
\end{aligned}
$$

ただし, $\otimes$ は限界積 $(a \otimes b=\max [a+b-1,0])$ である。

様相論理江抢いて，相対的可能性 [5]という概念がある。乙れは，数值を取り扱うあのではない。 ここでは, 相対的可能性の考え方を様相測度に適用して, 相対的可能性測度を定義し, 数值として取 り扱っている。

相対的可能性測度と同様に，相対的必然性測度 (R N)， 相対的不可能性測度 (R I )，相対的偶 然性測度（R C ）あ，それぞれ，(22)式，(23)式，(24)式のように定義できる。

(22) $\operatorname{RN}(\widetilde{\mathrm{B}} / \widetilde{\mathrm{A}}) \triangleq \max [\operatorname{NES}(\widetilde{\mathrm{B}} / \widetilde{\mathrm{A}})-\mathrm{NES}(\widetilde{\widetilde{B}} / \widetilde{\mathrm{A}}), 0]$

(23) $\operatorname{RI}(\widetilde{\mathrm{B}} / \widetilde{\mathrm{A}}) \triangleq \max [\operatorname{IMP}(\widetilde{\mathrm{B}} / \widetilde{\mathrm{A}})-\operatorname{IMP}(\widetilde{\mathrm{B}} / \widetilde{\mathrm{A}}), 0]$

(24) $\operatorname{RC}(\widetilde{\mathrm{B}} / \widetilde{\mathrm{A}}) \triangleq \max [\operatorname{CONT}(\widetilde{\mathrm{B}} / \widetilde{\mathrm{A}})-\operatorname{CONT}(\widetilde{\widetilde{\mathrm{B}}} / \widetilde{\mathrm{A}}), 0]$

(5)式〜7)式から, 次の等式が成立する。

(25) $\operatorname{RP}(\widetilde{\mathrm{B}} / \widetilde{\mathrm{A}})=\mathrm{RN}(\widetilde{\mathrm{B}} / \widetilde{\mathrm{A}})$

(26) $\operatorname{RI}(\widetilde{B} / \widetilde{A})=\operatorname{RC}(\widetilde{B} / \widetilde{A})$

(27) $\operatorname{RI}(\widetilde{\mathrm{B}} / \widetilde{\mathrm{A}})=\operatorname{RP}(\overline{\widetilde{B}} / \widetilde{\mathrm{A}})$

次に, 相対的可能性測度と双対な関係にある双対相対的可能性測度を定義する。

[定義 2] 双対相対的可能性測叟（D R P）は，次のように定義される。

(28) $\operatorname{DRP}(\widetilde{\mathrm{B}} / \widetilde{\mathrm{A}}) \triangleq 1-\mathrm{RP}(\widetilde{\widetilde{B}} / \widetilde{\mathrm{A}})$

$$
=\operatorname{POS}(\widetilde{\mathrm{B}} / \widetilde{\mathrm{A}}) \oplus \mathrm{NES}(\widetilde{\mathrm{B}} / \widetilde{\mathrm{A}})
$$

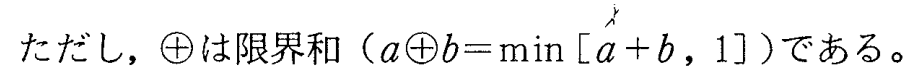

同様にして, 双対相対的必然性測度 (D R N), 双対相対的不可能性測度（DR I）および, 双対 相対的偶然性測度 (DR C) が定義できる。

ファジィ集合 $\widetilde{A} ， \widetilde{B}$ が与えられたときのR P ( $\widetilde{B} / \widetilde{A}), D R P(\widetilde{B} / \widetilde{A})$ をそれぞれ, 図 2 , 図 3 に 示す。 


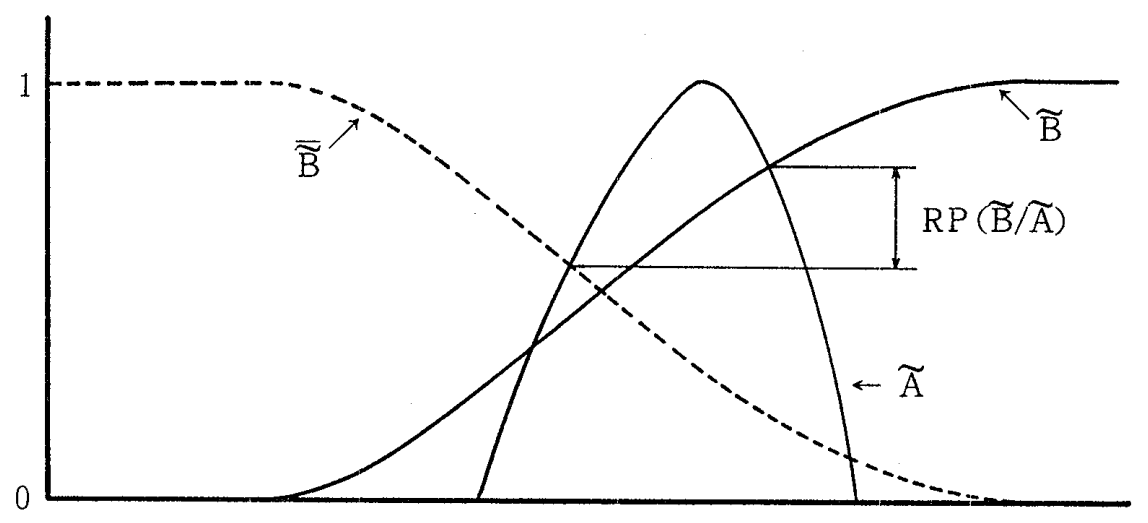

図 2 相対的可能性測度RP ( $\widetilde{B} / \widetilde{A})$

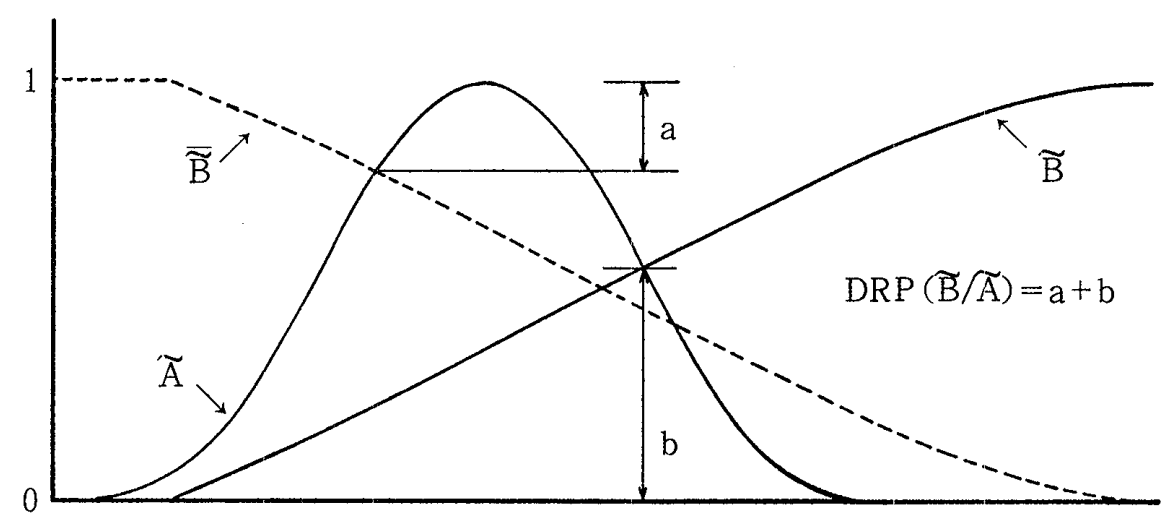

図 3 双対相対的可能性測度DRP( $\widetilde{B} / \widetilde{A})$

相対的可能性測度および双対相対的可能性測度の定義より，次の関係が成立する。

(i) $\mathrm{RP}(\widetilde{\mathrm{B}} / \widetilde{\mathrm{A}})>0$ ならば, $\mathrm{DRP}(\widetilde{\mathrm{B}} / \widetilde{\mathrm{A}})=1$

(ii) $\mathrm{D} \mathrm{RP}(\widetilde{\mathrm{B}} / \widetilde{\mathrm{A}})<1$ ならば, $\mathrm{RP}(\widetilde{\mathrm{B}} / \widetilde{\mathrm{A}})=0$

このととから，次の等式が成立する。

(29) $\operatorname{RP}(\widetilde{\mathrm{B}} / \widetilde{\mathrm{A}})+\mathrm{DRP}(\widetilde{\mathrm{B}} / \widetilde{\mathrm{A}})=\operatorname{POS}(\widetilde{\mathrm{B}} / \widetilde{\mathrm{A}})+\mathrm{NES}(\widetilde{\mathrm{B}} / \widetilde{\mathrm{A}})$

(30) $\quad \operatorname{RP}(\widetilde{B} / \widetilde{A}) \otimes D R P(\widetilde{B} / \widetilde{A})=R P(\widetilde{B} / \widetilde{A})$

(31) $\operatorname{RP}(\widetilde{\mathrm{B}} / \widetilde{\mathrm{A}}) \oplus \mathrm{DRP}(\widetilde{\mathrm{B}} / \widetilde{\mathrm{A}})=\mathrm{DRP}(\widetilde{\mathrm{B}} / \widetilde{\mathrm{A}})$

(30)式および(31)式は, 相対的可能性の相対的な測度およびそれと双対な測度は, 再び相対的可能性測 
度および双対相対的可能性測度になるととを示している。

また, $\widetilde{\mathrm{B}}_{1} \subseteq \widetilde{\mathrm{B}}_{2}$ とすると, 次の不等式が成立する。

(32) $\quad \operatorname{RPP}\left(\widetilde{\mathrm{B}}_{1} / \widetilde{\mathrm{A}}\right) \geqq \operatorname{RP}\left(\widetilde{\mathrm{B}}_{1} / \widetilde{\mathrm{A}}\right)$

(33) $\quad \mathrm{RP}\left(\widetilde{\mathrm{B}}_{1} / \widetilde{\mathrm{A}}\right) \leqq \mathrm{RP}\left(\widetilde{\mathrm{B}}_{2} / \widetilde{\mathrm{A}}\right)$

(34) $\operatorname{DRP}\left(\widetilde{\mathrm{B}}_{1} / \widetilde{\mathrm{A}}\right) \leqq \mathrm{DRP}\left(\widetilde{\mathrm{B}}_{2} / \widetilde{\mathrm{A}}\right)$

乙てで, 相対的可能性測度とPrade の様相測度の関係について述べる。

[命題 2] $\widetilde{A}$ が正規なファジィ集合であるとき, N E S ( $\widetilde{B} / \widetilde{A})>0.5$ ならば， R P $(\widetilde{B} / \widetilde{A})>0$ で であり, RP $(\widetilde{\mathrm{B}} / \widetilde{\mathrm{A}})>0$ ならば, $\operatorname{POS}(\widetilde{\mathrm{B}} / \widetilde{\mathrm{A}})>0.5$ である。

（証明） $\quad \mathrm{NES}(\widetilde{\mathrm{B}} / \widetilde{\mathrm{A}})>0.5$ と(12)式より, $\mathrm{POS}(\widetilde{\mathrm{B}} / \widetilde{\mathrm{A}})>0.5$ となる。また，(7)式より, P O S $(\overline{\widetilde{B}} / \widetilde{A})=1-\mathrm{NES}(\widetilde{\mathrm{B}} / \widetilde{\mathrm{A}})$ であるから, $\operatorname{POS}(\widetilde{\widetilde{B}} / \widetilde{\mathrm{A}})<0.5$ となる。したがって,

$\operatorname{POS}(\widetilde{\mathrm{B}} / \widetilde{\mathrm{A}})-\operatorname{POS}(\overline{\widetilde{B}} / \widetilde{\mathrm{A}})>0$

となり, RP ( $\widetilde{\mathrm{B}} / \widetilde{\mathrm{A}})>0$ となる。

次に, RP $(\widetilde{\mathrm{B}} / \widetilde{\mathrm{A}})>0$ のとき, $\operatorname{POS}(\widetilde{\mathrm{B}} / \widetilde{\mathrm{A}}) \leqq 0.5$ と仮定すると。(7)式より, $\mathrm{NES}(\overline{\widetilde{B}} / \widetilde{\mathrm{A}}) \geqq 0.5$ となる。さらに, (12)式より, POS $(\widetilde{\widetilde{B}} / \widetilde{\mathrm{A}}) \geqq 0.5$ となる。したがって,

$\operatorname{POS}(\widetilde{\mathrm{B}} / \widetilde{\mathrm{A}})-\operatorname{POS}(\widetilde{\mathrm{B}} / \widetilde{\mathrm{A}}) \leqq 0$

となり， R P $(\widetilde{\mathrm{B}} / \widetilde{\mathrm{A}})=0$ となる。乙れは, $\mathrm{R} P(\widetilde{\mathrm{B}} / \widetilde{\mathrm{A}})>0$ なる仮定に反する。

（証明終り）

[命題 3] $\mathrm{NES}(\widetilde{\mathrm{B}} / \widetilde{\mathrm{A}})>\operatorname{IMP}(\widetilde{\mathrm{B}} / \widetilde{\mathrm{A}})$ であるならば, またそのときに限り, $\mathrm{R} P(\widetilde{\mathrm{B}} / \widetilde{\mathrm{A}})>0$ である。

（証明） $\operatorname{NES}(\widetilde{\mathrm{B}} / \widetilde{\mathrm{A}})>\mathrm{I} \mathrm{MP}(\widetilde{\mathrm{B}} / \widetilde{\mathrm{A}})$ であると仮定すると，

$\operatorname{NES}(\widetilde{\mathrm{B}} / \widetilde{\mathrm{A}})-\operatorname{IMP}(\widetilde{\mathrm{B}} / \widetilde{\mathrm{A}})>0$

となる。(5)式を用いると，

$\operatorname{NES}(\widetilde{B} / \widetilde{A})-(1-\operatorname{POS}(\widetilde{B} / \widetilde{A}))=\operatorname{NES}(\widetilde{B} / \widetilde{A})+\operatorname{POS}(\widetilde{B} / \widetilde{A})-1>0$

となる。したがって, R P ( $\widetilde{\mathrm{B}} / \widetilde{\mathrm{A}})>0$ となる。

逆は，上の証明を逆にたどればよい。

（証明終り）

命題 3 の証明より,

(35) $\quad \operatorname{RP}(\widetilde{\mathrm{B}} / \widetilde{\mathrm{A}})=\max [\operatorname{NES}(\widetilde{\mathrm{B}} / \widetilde{\mathrm{A}})-\operatorname{IMP}(\widetilde{\mathrm{B}} / \widetilde{\mathrm{A}}), 0]$

と書ける。つまり, 相対的可能性測度は $\widetilde{\mathrm{A}}$ の要素が $\widetilde{\mathrm{B}}$ に属する必然性が, 药に属する不可能性より大 きい度合と考えるととができるととを示している。 


\section{3. 様相測度に基づく意思決定}

いま，図４亿示すように意思決定者が選べる代替案が $\mathrm{n}$ 個あり，そのそれぞれの代替案を選んだと きの実現しうる結果 (可能性分布) $\widetilde{\mathrm{B}}_{\mathrm{i}}$ がわかっているとする。また，意思決定者にとって望ましい結 果（ファジィ目標） $\widetilde{A} か ゙ 与 え ら れ て い る と す る 。 た た ゙ し ， \widetilde{A} ， \widetilde{B}_{i}$ は正規なファジィ集合とする。
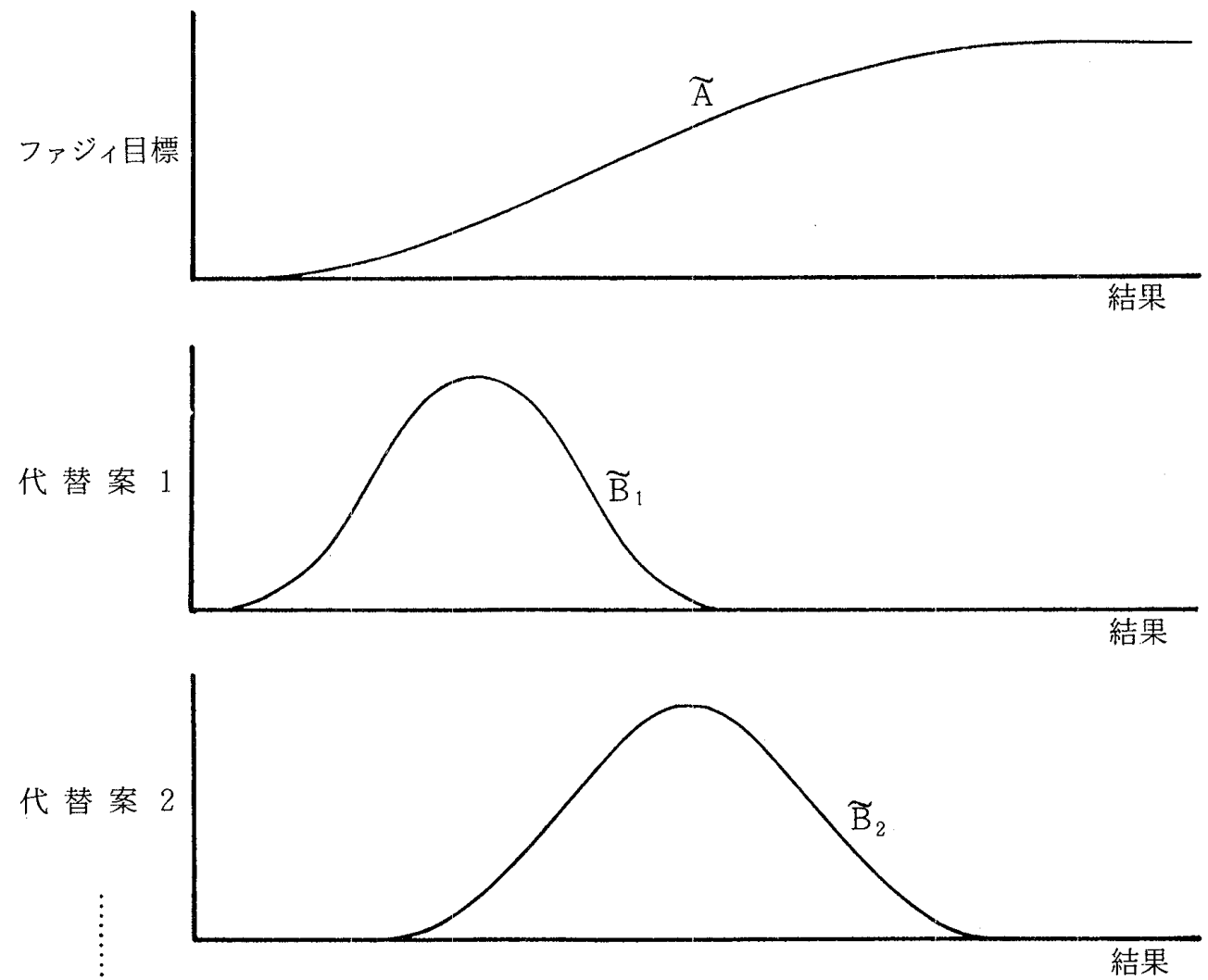

結果

代替案 $n$

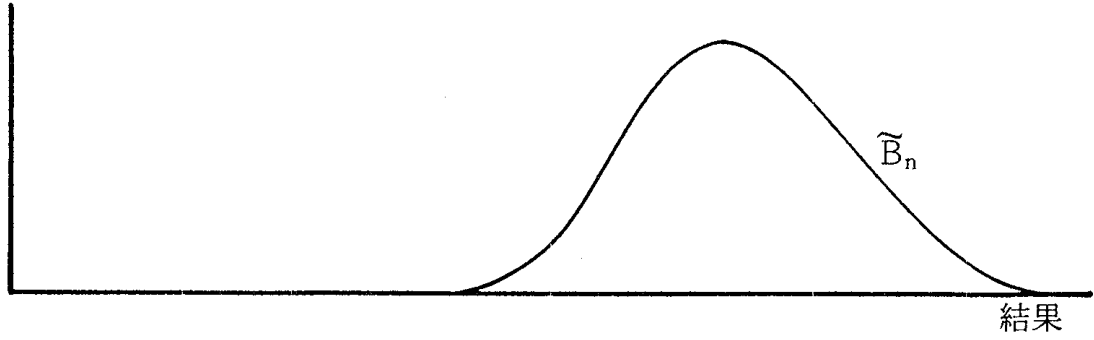

図 4 ファジィ目標 $\widetilde{A}$ と可能性分布 $\widetilde{B}_{i}$

このとき，様相の概念から，意思決定者のとりうる決定方式について考察する。な扔，不可能性測 度の最小化（最大化）は，(5)式より可能性測度の最大化（最小化）と等価であり，偶然性測度の最小 化（最大化）は，必然性測度の最大化（最小化）と等価であるので，以下では，可能性測度と必然性 測度についてのみ述べる。また，相対的な様相測度についても同様に，相対的可能性測度と双対相対 的可能性測度についてのみ述べる。 
まず, 可能性測度と必然性測度に基づく場合から考える。乙の場合, $\widetilde{\mathrm{A}}, \widetilde{\mathrm{B}_{i}}$ の肯定, 否定の組み合 せが 4 通り，そのそれぞれについて，いずれを基準にするかという順列で 2 通り，また，それぞれに ついて, 可能性測度を用いるか, 必然性測度を用いるがより 2 通り考えられ, 結局, $4 \times 2 \times 2=16$

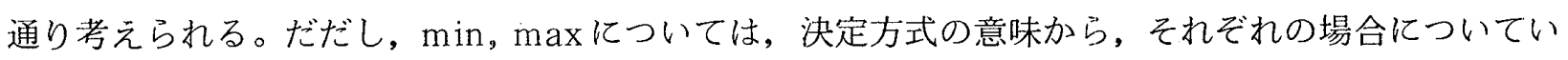
ずれかに定まる。乙れらを(7)式，(8)式，(10)式により, 等価なものをまとめると，I～IVの 4 種類に分 類される。

\section{表1 可能性と必然性に基づく決定方式}

\begin{tabular}{|c|c|c|c|}
\hline I & $\begin{array}{l}\text { ・望ましい集合が実現しうる可能性を最大にする。 } \\
\text { ・実現しうる集合が望ましい可能性を最大にする。 } \\
\text { ・実現しうる集合が望ましくない必然性を最小にする。 } \\
\text { ・望ましい集合が夹現しない必然性を最小にする。 }\end{array}$ & $\begin{array}{l}\max \\
\max \\
\min \\
\min \end{array}$ & $\begin{array}{l}\operatorname{POS}\left(\widetilde{B}_{i} / \widetilde{A}\right) \\
\operatorname{POS}\left(\widetilde{A} / \widetilde{B}_{i}\right) \\
\operatorname{NES}\left(\widetilde{A} / \widetilde{B}_{i}\right) \\
\operatorname{NES}\left(\widetilde{B}_{i} / \widetilde{A}\right)\end{array}$ \\
\hline II & $\begin{array}{l}\text { ・望ましくない集合が実現しない可能性を最大にする。 } \\
\text { ・実現しない集合が望ましくない可能性を最大にする。 } \\
\text { ・望ましくない集合が実現しうる必然性を最小にする。 } \\
\text { ・実現しない集合が望ましい必然性を最小にする。 }\end{array}$ & $\begin{array}{l}\max \\
\max \\
\min \\
\min \end{array}$ & $\begin{array}{l}\operatorname{POS}\left(\widetilde{\mathrm{B}}_{\mathrm{i}} / \widetilde{\widetilde{A}}\right) \\
\operatorname{POS}\left(\widetilde{\widetilde{A}} /{\widetilde{\widetilde{B}_{i}}}\right) \\
\operatorname{NES}\left(\widetilde{\mathrm{B}}_{i} / \widetilde{\mathrm{A}}\right) \\
\operatorname{NES}\left(\widetilde{\mathrm{A}} / \widetilde{\mathrm{B}}_{i}\right)\end{array}$ \\
\hline III & $\begin{array}{l}\text { ・望ましい集合が実現しうる必然性を最大にする。 } \\
\text { ・実現しない集合が望ましくない必然性を最大にする。 } \\
\text { ・望ましい集合が実現しない可能性を最小にする。 } \\
\text { ・実現しない集合が望ましい可能性を最小にする。 }\end{array}$ & $\begin{array}{l}\max \\
\max \\
\min \\
\min \end{array}$ & $\begin{array}{l}\operatorname{NES}\left(\widetilde{B}_{i} / \widetilde{A}\right) \\
\operatorname{NES}\left(\widetilde{\widetilde{A}}_{\widetilde{B}_{i}}\right) \\
\operatorname{POS}\left(\widetilde{\widetilde{B}}_{i} / \widetilde{A}\right) \\
\operatorname{POS}\left(\widetilde{A} / \widetilde{B}_{i}\right)\end{array}$ \\
\hline IV & $\begin{array}{l}\text { ・実現しうる集合が望ましい必然性を最大にする。 } \\
\text { ・望ましくない集合が実現しない必然性を最小にする。 } \\
\text { ・実現しうる集合が望ましくない可能性を最小にする。 } \\
\text { ・望ましくない集合が実現しうる可能性を最小にする。 }\end{array}$ & $\begin{array}{l}\max \\
\max \\
\min \\
\min \end{array}$ & $\begin{array}{l}\operatorname{NES}\left(\widetilde{A} / \widetilde{B}_{i}\right) \\
\operatorname{NES}\left(\widetilde{\widetilde{B}}_{i} / \widetilde{\widetilde{A}}\right) \\
\operatorname{POS}\left(\widetilde{\widetilde{A}} / \widetilde{B}_{i}\right) \\
\operatorname{POS}\left(\widetilde{B}_{i} / \widetilde{\widetilde{A}}\right)\end{array}$ \\
\hline
\end{tabular}

次に，相対的な様相測度に基づく場合を考える。いま，実現しうる結果の望ましい可能性が，望ま しくない可能性よりも大きい度合を最大にしたという決定方式を考える。この問題は, 相対的可能性 測度を用いて,

(36) $\max \operatorname{RP}\left(\widetilde{\mathrm{A}} / \widetilde{\mathrm{B}}_{\mathrm{i}}\right)$

と書ける。ところで, この決定方式では, 実現しうる結果の望ましい可能性が, 望ましくない可能性 より常に小さいときには, すべての代替案が無差別となる。しかし, てのような場合, 一般に, 意思 決定者は望ましい可能性が，望ましくない可能性よりむ小さい度合を最小にする代替案を選択する。 
すなわち,

(37) $\min \operatorname{RP}\left(\overline{\widetilde{\mathrm{A}}} / \widetilde{\mathrm{B}}_{\mathrm{i}}\right)$

なる代替案を選ぶ。さらに，(37)式は，

(38) $\max \operatorname{DRP}\left(\widetilde{\mathrm{A}} / \widetilde{\mathrm{B}}_{\mathrm{i}}\right)$

と等価であり，乙れと(36)式を統合すると，R P $\left(\widetilde{A} / \widetilde{B}_{i}\right)>0$ ならば，常にD R P $\left(\widetilde{A} / \widetilde{B}_{i}\right)=1$ であり， D R P $\left(\widetilde{A} / \widetilde{B}_{i}\right)<1$ ならば, 常にR P $\left(\widetilde{A} / \widetilde{B}_{i}\right)=0$ であるととから,

(39) $\max \operatorname{RP}\left(\widetilde{\mathrm{A}} / \widetilde{\mathrm{B}}_{\mathrm{i}}\right)+\mathrm{DRP}\left(\widetilde{\mathrm{A}} / \widetilde{\mathrm{B}}_{\mathrm{i}}\right)$

となる。また,(29)式より，

(40) $\max \operatorname{POS}\left(\widetilde{\mathrm{A}} / \widetilde{\mathrm{B}}_{\mathrm{i}}\right)+\mathrm{NES}\left(\widetilde{\mathrm{A}} / \widetilde{\mathrm{B}}_{\mathrm{i}}\right)$

となる。その他の場合屯同様に考えると，表 2 のように，8通りの決定方式が考えられ，V〜徂の 4 種類に分類される。

\section{表 2 相対的な様相測度に基つく決定方式}

\begin{tabular}{|c|c|c|c|}
\hline $\mathrm{V}$ & $\begin{array}{l}\max \\
\min \end{array}$ & $\begin{array}{l}\operatorname{RP}\left(\widetilde{\mathrm{B}}_{i} / \widetilde{\mathrm{A}}\right)+\operatorname{DRP}\left(\widetilde{\mathrm{B}}_{i} / \widetilde{\mathrm{A}}\right) \Leftrightarrow \max \\
\operatorname{RP}\left(\widetilde{\widetilde{B}}_{i} / \widetilde{\mathrm{A}}\right)+\operatorname{DRP}\left({\widetilde{\widetilde{B}_{i}}} / \widetilde{\mathrm{A}}\right) \Leftrightarrow \min \end{array}$ & $\begin{array}{l}\operatorname{POS}\left(\widetilde{B}_{i} / \widetilde{A}\right)+N \operatorname{ES}\left(\widetilde{B}_{i} / \widetilde{A}\right) \\
\operatorname{POS}\left(\widetilde{B}_{i} / \widetilde{A}\right)+N \operatorname{ES}\left(\widetilde{B}_{i} / \widetilde{A}\right)\end{array}$ \\
\hline $\mathrm{VI}$ & $\begin{array}{l}\max \\
\min \end{array}$ & $\begin{array}{l}\operatorname{RP}\left(\widetilde{A} / \widetilde{B}_{i}\right)+D R P\left(\widetilde{A} / \widetilde{B}_{i}\right) \Leftrightarrow \max \\
\operatorname{RP}\left(\widetilde{\widetilde{A}} / \widetilde{B}_{i}\right)+\operatorname{DPP}\left(\widetilde{\widetilde{A}} / \widetilde{B}_{i}\right) \Leftrightarrow \min \end{array}$ & $\begin{array}{l}\operatorname{POS}\left(\widetilde{A} / \widetilde{B}_{i}\right)+N \operatorname{ES}\left(\widetilde{A} / \widetilde{B}_{i}\right) \\
\operatorname{POS}\left(\widetilde{A} / \widetilde{B}_{i}\right)+N \operatorname{ES}\left(\widetilde{\widetilde{A}} / \widetilde{B}_{i}\right)\end{array}$ \\
\hline VII & $\begin{array}{l}\max \\
\min \end{array}$ & $\begin{array}{l}\operatorname{RP}\left(\overline{\widetilde{B}}_{i} / \overline{\widetilde{A}}\right)+\operatorname{DRP}\left(\overline{\widetilde{B}}_{i} / \overline{\widetilde{A}}\right) \Leftrightarrow \max \\
\operatorname{RP}\left(\widetilde{B}_{i} / \widetilde{\widetilde{A}}\right)+\operatorname{DPP}\left(\widetilde{B}_{i} / \widetilde{\widetilde{A}}\right) \Leftrightarrow \min \end{array}$ & $\begin{array}{l}\operatorname{POS}\left({\widetilde{\mathrm{B}_{i}}}_{i} / \overline{\widetilde{A}}\right)+N \operatorname{ES}\left(\overline{\widetilde{B}}_{i} / \overline{\widetilde{A}}\right) \\
\operatorname{PoS}\left(\widetilde{B}_{i} / \overline{\widetilde{A}}\right)+N \operatorname{NS}\left(\widetilde{B}_{i} / \overline{\widetilde{A}}\right)\end{array}$ \\
\hline VIII & $\begin{array}{l}\max \\
\min \end{array}$ & $\begin{array}{l}\operatorname{RP}\left(\overline{\widetilde{A}} / \overline{\widetilde{B}}_{i}\right)+\operatorname{DRP}\left(\overline{\widetilde{A}} / \overline{\widetilde{B}}_{i}\right) \Leftrightarrow \max \\
\operatorname{RP}\left(\widetilde{\mathrm{A}} / \overline{\widetilde{B}}_{i}\right)+\operatorname{DPP}\left(\widetilde{\mathrm{A}} / \widetilde{\widetilde{B}}_{i}\right) \Leftrightarrow \min \end{array}$ & $\begin{array}{l}\operatorname{POS}\left(\widetilde{\widetilde{A}} / \widetilde{\widetilde{B}}_{i}\right)+N \operatorname{ES}\left(\overline{\widetilde{A}} / \overline{\widetilde{B}}_{i}\right) \\
\operatorname{POS}\left(\widetilde{A} / \widetilde{\widetilde{B}}_{i}\right)+N \operatorname{ES}\left(\widetilde{A} / \widetilde{\widetilde{B}}_{i}\right)\end{array}$ \\
\hline
\end{tabular}

ここで，乙れらの決定方式と意思決定者の危険に対する態度について考察する。

ファジィ集合の包含関係 $\widetilde{\mathrm{B}}_{\mathrm{i}} \subseteq \widetilde{\mathrm{B}}_{\mathrm{j}}$ は，それぞれのメンバシップ関数 $\mu_{\widetilde{\mathrm{B}}_{\mathrm{i}}}, \mu_{\widetilde{\mathrm{B}}_{\mathrm{j}}}$ を用いて, $\mu_{\widetilde{\mathrm{B}}_{\mathrm{i}}}(y) \leqq \mu_{\mathrm{B}_{\mathrm{j}}}(y)$ と定義される。したがって, $\widetilde{\mathrm{B}}_{\mathrm{i}} \subseteq \widetilde{\mathrm{B}}_{\mathrm{j}}$ であるとき, 可能性分布 $\widetilde{\mathrm{B}}_{\mathrm{j}}$ の方が, 可能性分布 $\widetilde{\mathrm{B}}_{\mathrm{i}}$ 上り不確実性 が高いといえる。ゆえに，意思決定者の危険に対する態度を次のように定義する。

[定義 3 ] $\widetilde{\mathrm{B}}_{\mathrm{i}} \subseteq \widetilde{\mathrm{B}}_{\mathrm{j}}$ なる任意の可能性分布 $\widetilde{\mathrm{B}}_{\mathrm{i}}, \widetilde{\mathrm{B}}_{\mathrm{j}}$ が与えられたとき，意思決定者が常に $\widetilde{\mathrm{B}}_{\mathrm{i}}$ より $\widetilde{\mathrm{B}}_{\mathrm{j}}$ を選好または， $\widetilde{\mathrm{B}}_{\mathrm{i}}$ と $\widetilde{\mathrm{B}}_{j}$ が無差別であるならば，その意思決定者の危険に対する態度は危険受容型で ある。

[定義 4] $\widetilde{\mathrm{B}}_{\mathrm{i}} \subseteq \widetilde{\mathrm{B}}_{\mathrm{j}}$ なる任意の可能性分布 $\widetilde{\mathrm{B}}_{\mathrm{i}}, \widetilde{\mathrm{B}}_{\mathrm{j}}$ が与えられたとき, 意思決定者が常に $\widetilde{\mathrm{B}}_{\mathrm{j}}$ より $\widetilde{\mathrm{B}}_{\mathrm{i}}$ を 
選好または， $\widetilde{\mathrm{B}}_{\mathrm{i}}$ と $\widetilde{\mathrm{B}}_{\mathrm{j}}$ が無差別であるならば，その意思決定者の危険に対する態度は危険回避型である。

［定義 5 ］ 意思決定者の危険に対する態度が危険受容型でも，危険回避型であないならば，その意 思決定者の危険に対する態度は危険中立型である。

決定方式 I〜UIIについて，次のようなととがいえる。

[命題 4 ] 決定方式 I, III, V による決定は, 危険受容型であり, 決定方式 II, IV, VII による決定 は，危険回避型である。また，決定方式VI，UIIによる決定は，危険中立型である。

（証明） $\widetilde{\mathrm{B}}_{\mathrm{i}} \subseteq \widetilde{\mathrm{B}}_{\mathrm{j}}$ ならば, $\widetilde{\mathrm{B}}_{\mathrm{i}} \supseteq \widetilde{\mathrm{B}}_{\mathrm{j}}$ であるとと,(13)式〜(15)式および，(33)式，(34)式より明らかである。 (証明終り)

以上をまとめると, 表 3 のようになる。こてで, 決定方式 I は $\max \operatorname{POS}\left(\widetilde{\mathrm{B}}_{\mathrm{i}} / \widetilde{\mathrm{A}}\right)$, 決定

表 3 決定方式と危険に対する態度の関係

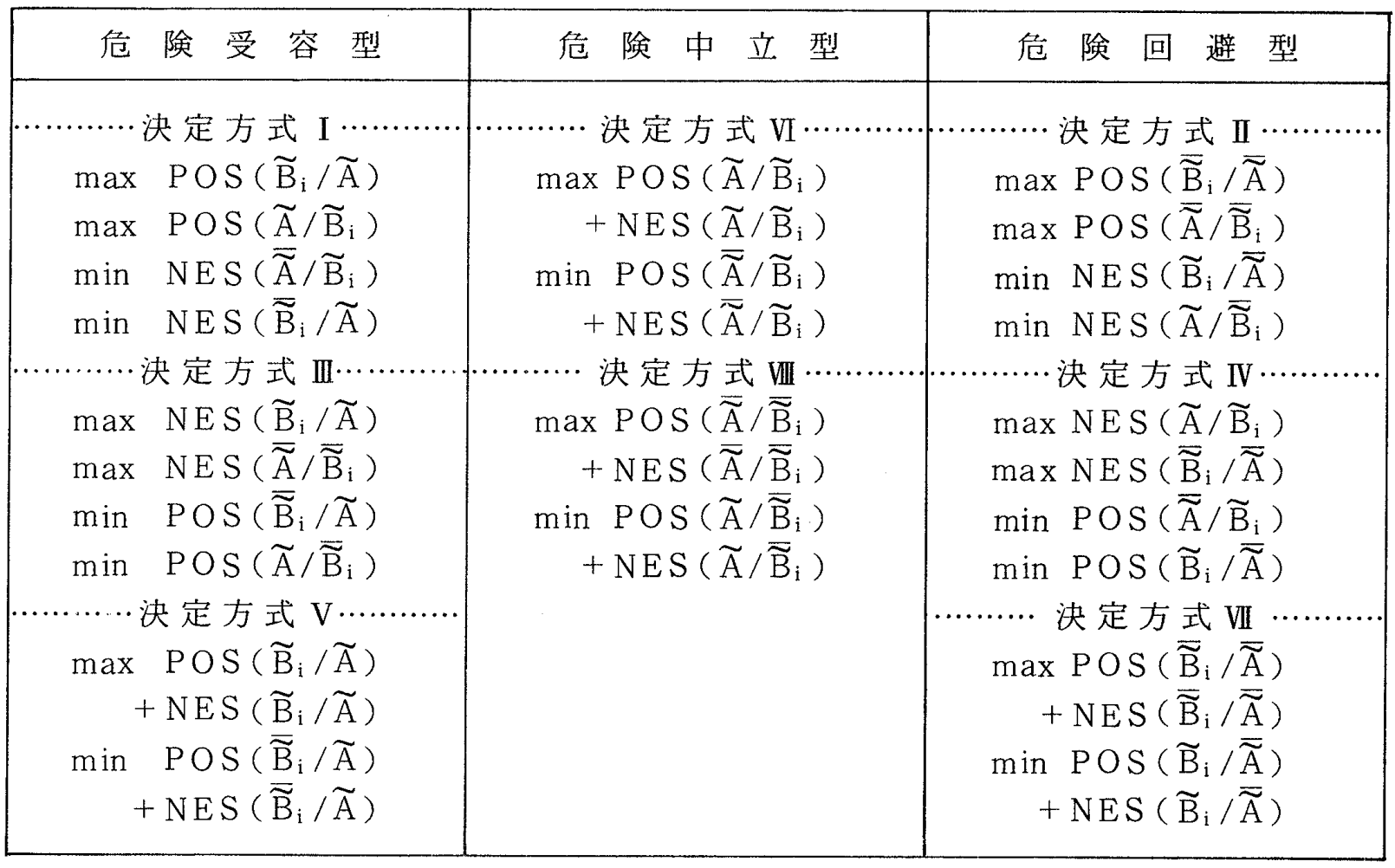

方式II は max POS $\left(\widetilde{\mathrm{B}}_{\mathrm{i}} / \widetilde{\mathrm{A}}\right)$, 決定方式吕は $\max \operatorname{NES}\left(\widetilde{\mathrm{B}}_{\mathrm{i}} / \widetilde{\mathrm{A}}\right)$, 決定方式IV $\max \mathrm{NES}\left(\widetilde{\mathrm{A}} / \widetilde{\mathrm{B}}_{\mathrm{i}}\right)$ として, 決定方式 $\mathrm{I} \sim \mathrm{IV}$ までを解釈すると，次のようになる。決定方式 I は，ある望ましい結果が実 現しうるようにするため, 決定方式亚は，すべての望ましい結果が実現しうるようにするため，いず れあ, 実現しうる結果が広範囲にわたるものを選好する。それゆえ, 危険受容型となる。また, 決定 方式IIは, ある望ましくない結果が奏現しないようにするため, 決定方式IVは，すべての実現しうる 結果が望ましい結果であるようにするため, いずれも, 実現しうる結果の範囲の狭いもの（実現しえ ない結果の範囲の広いもの）を選好する。それゆえ, 危険回避型となる。（図 5 参照）さらに, 決 
望ましい結果の集合＼cjkstart害現しうる結果の集合

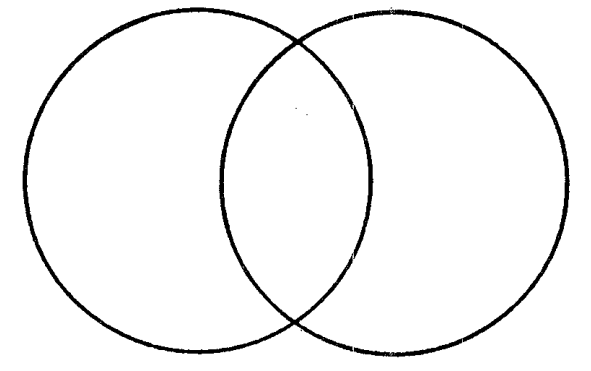

。決定方式 I $\max \operatorname{POS}\left(\widetilde{B}_{\mathrm{i}} / \widetilde{\mathrm{A}}\right)$

望ましくない結果の集合＼cjkstart実現しない結果の集合

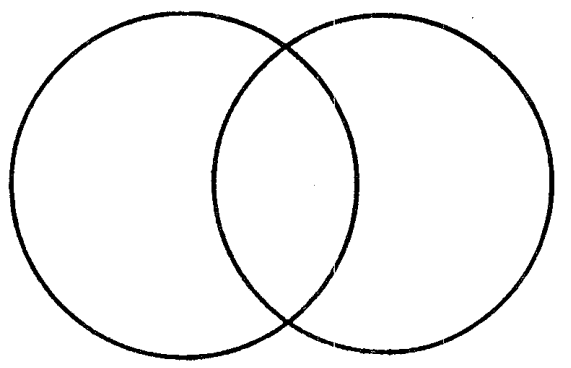

。決定方式 II $\max \operatorname{POS}\left(\overline{\widetilde{B}_{i} / \overline{\widetilde{A}}}\right)$
実現しうる結果の集合

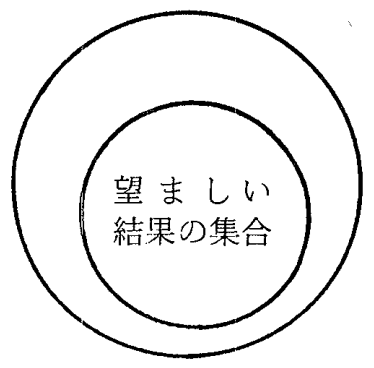

。決定方式而 $\max \operatorname{NES}\left(\widetilde{B}_{i} / \widetilde{A}\right)$

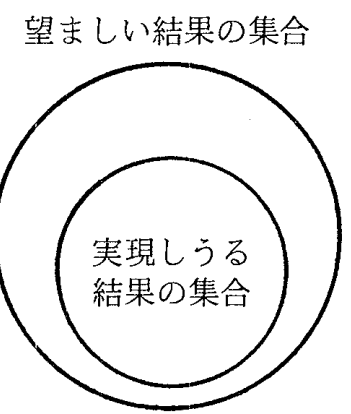

。決定方式IV max NES $\left(\widetilde{A} / \widetilde{B}_{i}\right)$

図 5 決定方式 I IV の図的解釈

定方式Vは，決定方式 I と四を合わせたものであるから，危険受容型となり，決定方式VIは，決定方 式II とIVを合わせたあのであるから，危険回避型となる。また，決定方式Vおよび四は，それぞれ， 決定方式 I と IV, 決定方式II とIIIを結合したものであるから，危険中立型となる。

また，決定方式 I 抢よび四では，望ましい結果の生起については考慮しているが，望ましくない結 果の生起については考慮していない。決定方式II およびIVでは, 望ましい結果の生起については考慮 せず，望ましくない結果の生起についてのみ取り扱っている。この相異点から解釈して屯，命題 4 は 理解できる。

このように，様相概念に基づく決定方式は，決定方式自体に意思決定者の危険に対する態度が表現 される。

\section{4. ファジィ多目的線形計画問題への応用}

\section{1 定 式 化}

本章では, 様相測度に基づく決定方式を，ファジィ多目的線形計画問題へ応用する。ファジィ多目 的線形計画問題を次のように表わす。 
(41) $\quad\left\{\begin{array}{l}\widetilde{y}_{1}=\widetilde{a}_{1} \mathrm{x} \gtrsim \mathrm{b}_{1} \\ \widetilde{y}_{2}=\widetilde{a}_{2} \mathrm{x} \gtrsim \mathrm{b}_{2} \\ \ldots \ldots \ldots \ldots \ldots \ldots \ldots \\ \widetilde{y}_{\mathrm{m}}=\widetilde{\mathrm{a}}_{\mathrm{m}} \mathrm{x} \gtrsim \mathrm{b}_{\mathrm{m}}\end{array}\right.$

ここで, $\widetilde{\mathrm{a}}_{\mathrm{i}}=\left(\widetilde{\mathrm{a}}_{\mathrm{i} 1}, \widetilde{\mathrm{a}}_{\mathrm{i} 2}, \cdots, \widetilde{\mathrm{a}}_{\mathrm{in}}\right), \mathrm{x}=\left(x_{1}, x_{2}, \cdots, x_{\mathrm{n}}\right)^{\mathrm{t}}$ である。ファジィ係数 $\widetilde{\mathrm{a}}_{\mathrm{ij}}$ は, L-R ファジィ数 $\left(\mathrm{a}_{\mathrm{ij}}, \alpha_{\mathrm{ij}}, \beta_{\mathrm{ij}}\right)_{\mathrm{L}_{\mathrm{ij}} \mathrm{R}_{\mathrm{ij}}}[6]$ で表され, 係数のとりうる值を示している。 $\mathrm{L}_{\mathrm{ij}}, \mathrm{R}_{\mathrm{ij}}$ は, reference 関数 $[6]$ である。また， $b_{i}$ は意思決定者の十分満足できる值を示し，之 $b_{i}$ は, “だいたい $b_{i}$ 以上”というファジィ目標 $[7]$ を示している。

一般に, 各ファジィ目標は，単調増加なメンバシップ関数 $\mu_{\mathrm{i}}\left(y_{\mathrm{i}}\right)$ で表現される。目標全体のファジ

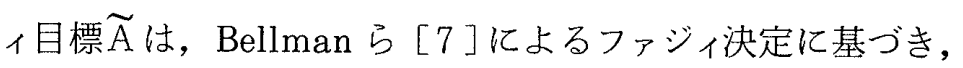

(42) $\quad \mu_{\widetilde{\AA}}(y)=\bigwedge_{i=1}^{\mathrm{m}} \mu_{\mathrm{i}}\left(y_{\mathrm{i}}\right)$

とする。

また，決定変数 $x$ に応じて実現しうるファジィ集合 $\widetilde{\mathrm{B}}$ は，直積を用いて，次のように表わされる。

(43) $\quad \mu_{\widetilde{\mathrm{B}}}(y)=\bigwedge_{1=1}^{\mathrm{m}} \mu_{\tilde{y}_{\mathrm{i}}}\left(y_{\mathrm{i}}\right)$

こてで, $\mu_{\tilde{y}_{\mathrm{i}}}\left(y_{\mathrm{i}}\right)$ はファジィ集合 $\tilde{y}_{\mathrm{i}}$ のメンバシップ関数である。

このとき，任意の $h \in(0,1]$ 亿対し， $(\widetilde{\mathrm{A}})_{h}$ 执よび $(\widetilde{\mathrm{A}})_{h}$ は非有界となり，[ $[\widetilde{\mathrm{B}}]_{h}$ は有界となるの で, 命題 1 より, NES $(\widetilde{\mathrm{B}} / \widetilde{\mathrm{A}})=0$ およびNES $(\widetilde{\mathrm{B}} / \overline{\widetilde{A}})=0$ となる。したがって, 決定方式 $I$, III およびUII無意味なものとなり，決定方式 I とV, 決定方式IVとVII 場合，決定方式として，I，IV，VIを考えれば十分である。

(17)式および(18)式により，各目標でとに分解して考えて定式化すると，それぞれ，次のようになる。

(a) 決定方式 I K基づく場合

(44) $\max h$

制約条件

(45) $\left\{\begin{array}{l}\mu_{\mathrm{i}}^{-1}(h) \leqq \widetilde{\mathrm{a}}_{\mathrm{i}}^{u}(h) x \quad(\mathrm{i}=1,2, \cdots, \mathrm{m}) \\ x \geqq 0, \quad 0 \leqq h \leqq 1\end{array}\right.$

（b）決定方式IVに基づく場合

(46) $\max h$

制約条件

(47)

$$
\left\{\begin{array}{l}
\mu_{i}^{-1}(h) \leqq \widetilde{a}_{1}^{1}(1-h) x \quad(i=1,2, \cdots, m) \\
x \geqq 0, \quad 0 \leqq h \leqq 1
\end{array}\right.
$$


(c) 決定方式VI飞基づく場合

(48) $\max h_{1}+h_{2}$

制約条件

(49) $\left\{\begin{array}{l}\mu_{\mathrm{i}}^{-1}\left(h_{1}\right) \leqq a_{\mathrm{i}}^{\mathrm{u}}\left(h_{1}\right) x \quad(i=1,2, \cdots, \mathrm{m}) \\ \mu_{\mathrm{i}}^{-1}\left(h_{2}\right) \leqq a_{i}\left(1-h_{2}\right) x \quad(i=1,2, \cdots, \mathrm{m}) \\ \mathrm{x} \geqq 0,0 \leqq h_{2} \leqq h_{1} \leqq 1\end{array}\right.$

ここで, $a_{i}^{u}(h)=\left(a_{i 1}^{u}(h), a_{i 2}^{u}(h), \cdots, a_{i n}^{u}(h)\right), \quad a_{i}^{l}(h)=\left(a_{i 1}^{l}(h), a_{i 2}^{l}(h), \cdots, a_{i n}^{1}(h)\right)$ あ゙あり,

(50) $\quad a_{i j}^{u}(h)=a_{i j}+\beta_{i j} R_{i j}^{-1}(h)$

(51) $a_{i j}^{1}(h)=a_{i j}-\alpha_{i j} L_{i j}^{-1}(h)$

である。

\section{2 解 法}

決定方式 I 抢よびIVに基づく場合は，よく知られているように，二分法とシンプレックス法の第 1 段階を繰り返すことにより，近似解を求めることができる $[4]$ 。ここでは，決定方式Vに基づく場 合の解法について述べる。

[定理 1$] \quad h_{1}=\mathrm{h}_{1}^{1}, h_{2}=\mathrm{h}_{2}^{1}$ として，(49)式を満たす $\mathrm{x}$ が存在するならば, $\mathrm{h}_{1}^{2} \leqq \mathrm{~h}_{1}^{1}$ かつ $\mathrm{h}_{2}^{2} \leqq \mathrm{~h}_{2}^{1}$ なる 任意の対 $\left(h_{1}^{2}, h_{2}^{2}\right)$ について，(49)式を満たす $x$ が存在する。

（証明）仮定より，

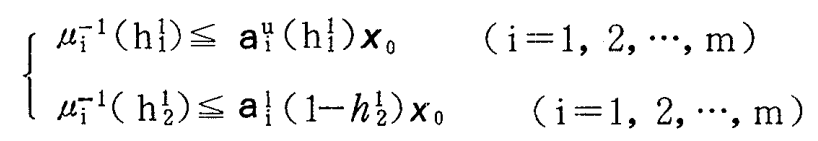

なる $x_{0} \geqq 0$ が存在する。

いま, $h_{1}^{1} \geqq h_{1}^{2}$ かつ $h_{2}^{1} \geqq h_{2}^{2}$ なる任意の対 $\left(h_{1}^{2}, h_{2}^{2}\right)$ そいて， $\mu_{i}\left(y_{i}\right)$ の単調増加性および refer ence関数 $L_{i j}, R_{i j}$ の強意減少性より,

$$
\begin{gathered}
\mu_{\mathrm{i}}^{-1}\left(h_{1}^{1}\right) \geqq \mu_{\mathrm{i}}^{-1}\left(h_{1}^{2}\right) \\
\mu_{\mathrm{i}}^{-1}\left(h_{2}^{1}\right) \geqq \mu_{\mathrm{i}}^{-1}\left(h_{2}^{2}\right) \\
L_{\mathrm{ij}}^{-1}\left(1-h_{2}^{1}\right) \geqq L_{\mathrm{ij}}^{-1}\left(1-h_{2}^{2}\right) \\
R_{\mathrm{ij}}^{-1}\left(h_{1}^{1}\right) \leqq R_{\mathrm{ij}}^{-1}\left(h_{1}^{2}\right) \\
\text { となる。また, (50)式, (51)式より, } \\
a_{\mathrm{ij}}^{u}\left(h_{1}^{1}\right) \leqq a_{\mathrm{ij}}^{\mathrm{u}}\left(h_{1}^{2}\right) \\
a_{i j}^{1}\left(1-h_{2}^{1}\right) \leqq a_{i j}^{1}\left(1-h_{2}^{2}\right)
\end{gathered}
$$

であるから， $x_{0}$ に対して，

$$
\left\{\begin{array}{l}
\mu_{i}^{-1}\left(h_{1}^{2}\right) \leqq a_{i}^{u}\left(h_{1}^{2}\right) x_{0} \quad(i=1,2, \cdots, m) \\
\mu_{i}^{-1}\left(h_{2}^{2}\right) \leqq a_{i}^{1}\left(1-h_{2}^{2}\right) x_{0}
\end{array}\right.
$$


となる。

(証明終り)

[系］ $h_{1}=\mathrm{h}_{1}^{1}, h_{2}=\mathrm{h}_{2}^{1}$ として，(49)式を満たす $x$ が存在しないならば， $\mathrm{h}_{1}^{2} \geqq \mathrm{~h}_{1}^{1}, \mathrm{~h}_{2}^{2} \geq \mathrm{h}_{2}^{1}$ なる任意の 対 $\left(h_{1}^{2}, h_{2}^{2}\right)$ につて, (49)式を満たす $x$ は存在しない。

定理 1 および系は, (49)式を満たす $x$ の存在する領域が $\mathrm{h}_{1}, \mathrm{~h}_{2}$ について連続であるととを示唆して いる。従って, $\mathrm{h}_{1}, \mathrm{~h}_{2}$ を与えて, (49)式を満たす解の存在を調べることを繰り返し, 最適解を求める次 の手順が考えられる。なお，乙てで述べる手順は，決定方式 I 拉よびIVにる解をも同時に求めよう とするものである。

[手順 1] $h=0$ として, シンプレックス法の第 1 段階を用いて，(47)式を満たす $x$ が存在するかり゙う か調べる。存在すれば, その解を $x_{0}$ とし, 手順 2 へ進む。存在しなければ, 手順27へ進む。

[手順 2] $h=1$ として, シンプレックス法の第 1段階を用いて, (47)式を満たす $x$ が存在するかどう か調べる。存在しなければ, 手順 3 へ進む。存在すれば, $x_{0}$ をいま求めた解として, 手順を終了する。 このとき, 決定方式 I, N , VIKよる解は唯一とは限らず, その解の一つがx

[手順 3 ] $s=0.5, \eta_{0}=0$ とする。

[手順 4] $h=\eta_{0}+s$ として, シンプレックス法の第 1 段階を用いで, (47)式を満たす $x$ が存在する かどうか調べる。存在すれば， $x_{0}$ をその解に， $\eta_{0}$ を $\eta_{0}+s$ 亿置き直す。

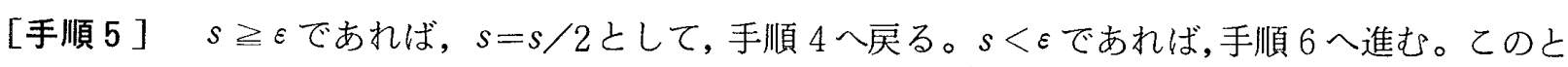
き, 解 $x_{0}$ は決定方式IVによる近似解之なっている。

[手順 6 ] $h_{1}=1, h_{2}=\eta_{0}$ として, シンプレックス法の第 1 段階を用いて，(49)式を満たす $x$ が存在 するかどうか調べる。存在しなければ，手順 7 へ進む。存在すれば， $x_{0}$ をその解に置き直し，手順を 終了する。乙のとき, 解 $x_{0}$ は決定方式 I, IV, VIによる近似解となっている。

[手順 7] $s=\left(1-\eta_{0}\right) / 2$ と置き直し， $\pi_{0}=\eta_{0}$ とする。

[手順 8] $h_{1}=\pi_{0}+s, h_{2}=\eta_{0}$ として, シンプレックス法の第 1 段階を用いて, (49)式を満たす $\mathrm{x}$ が 存在するかどうか調べる。存在すれば， $x_{0}$ をその解に， $\pi_{0}$ を $\pi_{0}+s$ に置き直す。

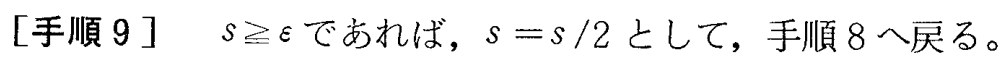

[手順10］ $h=1$ として, シンプレックス法の第 1 段階を用いて, (45)式を満たす $x$ が存在するかどう か調べる。存在すれば, $x_{1}$ をその解に置き, $\pi_{1}=1$ として, 手順14に進む。乙のとき, 決定方式 I に よる解は唯一とは限らず, その解の一つがx

[手順11］ $s=\left(1-\pi_{0}\right) / 2$, 之置き直し， $\pi_{1}=\pi_{0}$ とする。

[手順12］ $h=\pi_{1}+s$ として, シンプレックス法の第1 段階を用いて, (45)式を満たす $x$ が存在する かどうか調べる。存在すれば， $x_{1}$ をその解に， $\pi_{1}$ を $\pi_{1}+s$ に置き直す。

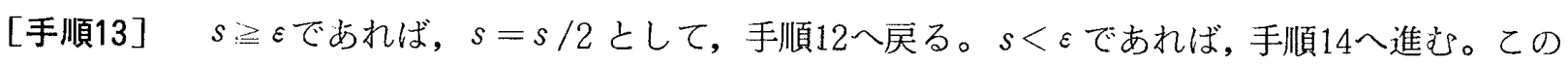
亡き, 解 $x$ は決定方式 I による近似解になっている。

[手順14] $h_{1}=\pi_{1}, h_{2}=0$ として, シンプレックス法の第 1 段階を用いて，(49)式を満たす $x$ が存在 
するかどうか調べる。存在しなければ, $\eta_{1}=0$ として, 手順18へ進む。

[手順15] $s=\pi_{1} / 2$ と置き直し， $\eta_{1}=0$ とする。

[手順16] $h_{1}=\pi_{1}, h_{2}=\eta_{1}+s$ として, シンプレックス法の第 1 段階を用いて，(49)式を満たす $x$ が存在するかどうか調べる。存在すれば， $x_{1}$ をその解に， $\eta_{1}$ を $\eta_{1}+s$ 亿置き直す。

[手順17] $s \geqq \varepsilon$ であば， $s=s / 2$ として，手順16へ戻る。

[手順18] $\pi_{0}+\eta_{0} \geqq \pi_{1}+\eta_{1}$ ならば, $r=\pi_{0}+\eta_{0}, \pi_{2}=\pi_{0}, \eta_{2}=\eta_{0}, x_{2}=x_{0}$ とする。 $\pi_{0}+\eta_{0}<$ $\pi_{1}+\eta_{1}$ ならば, $r=\pi_{1}+\eta_{1}, \pi_{2}=\pi_{1}, \eta_{2}=\eta_{1}, x_{2}=x_{1}$ とする。

[手順19] $\mathrm{H}=\left\{\left(\pi_{1}, \eta_{0}\right)\right\}$ 上する。

[手順20] $\mathrm{H}$ の要素 $(\pi, \eta)$ の中で, $\pi+\eta$ が最大となる要素を $\left(\pi^{*}, \eta^{*}\right)$ とし, $s=\pi^{*}+\eta^{*}-r$ と書き直す。

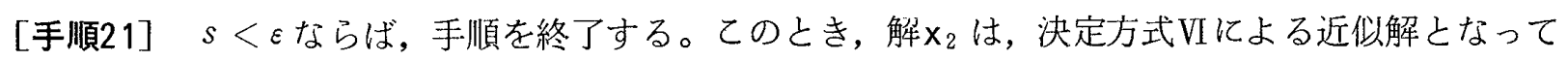
いる。

[手順22] $h_{1}=\pi^{*}-s, h_{2}=\eta^{*}-s$ として, シンプレックス法の第 1 段階を用いて, (49)式を満たす 解 $x$ が存在するかどうか調べる。存在すれば, $\pi_{3}=\pi^{*}-s, \eta_{3}=\eta^{*}-s$ とし, $s=s / 2$ と置き直す。

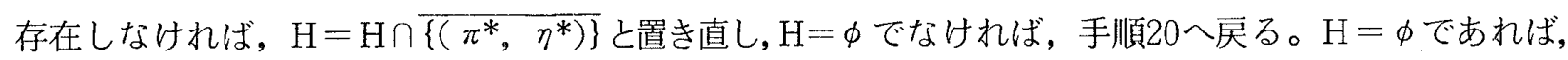
手順を終了する。乙のとき, 解 $x_{2}$ は, 決定方式IVによる最適解となる。

[手順23] $h_{1}=\pi_{3}+s, h_{2}=\eta_{3}+s$ として, シンプレックス法の第 1 段階を用いて, (49)式を満たす 解 $x$ が存在するかどうか調べる。存在すれば, その解を $x_{3}$ とし, $\pi_{3}=\pi_{3}+s, \eta_{3}=\eta_{3}+s$ と置き直 す。

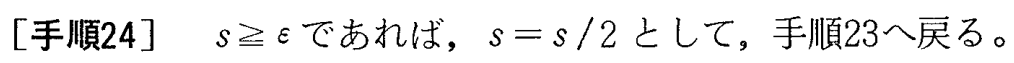

[手順25] $\pi_{3}+\eta_{3}>r$ であれば， $\pi_{2}=\pi_{3}, \eta_{2}=\eta_{3}, r=\pi_{3}+\eta_{3}, x_{2}=x_{3}$ と置き直す。

[手順26] $\mathrm{H}=\left[\mathrm{H} \cup\left\{\left(\pi_{3}+s, \eta^{*}\right),\left(\pi^{*}, \eta_{3}+s\right)\right\}\right] \cap \overline{\left\{\left(\pi^{*}, \eta^{*}\right)\right\}}$ と置き直して，手順20へ戻る。

[手順27] $h=0$ として, シンプレックス法の第 1段階を用いて，(45)式を満たす $x$ が存在するかど うか調べる。存在すれば, その解を $x_{1}$ とし, 手順28へ進む。存在しなければ, 決定方式 I, IV, VIの 解は存在しない。

[手順28］ $h=1$ として, シンプレックス法の第 1段階を用いて，(45)式を満たす $x$ が存在するかど うか調べる。存在すれば，その解を $x_{1}$ と置き直し，手順を終了する。乙のとき，決定方式IVによる解 は存在せず，決定方式 I およびVにによる解は $x_{1}$ となる。

[手順29] $s=0.5, \pi_{1}=0$ 亡する。

[手順30］ $h=\pi_{1}+s$ として, シンプレックス法の第 1 段階を用いて，(45)式を満たす $x$ が存在するか

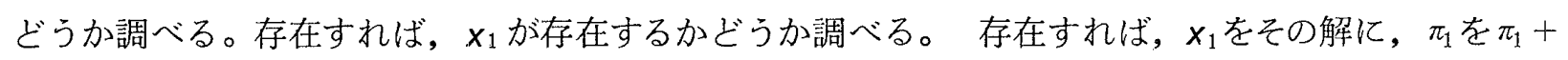
$s$ 亿置き直す。

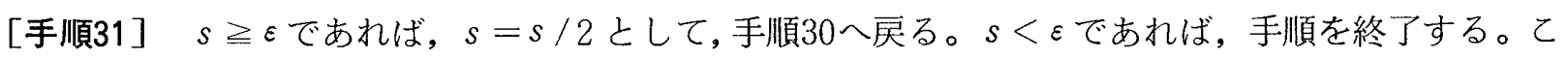
のとき, 決定方式IVによる解は存在せず, 決定方式 I およびVIによる解は $x_{1}$ となる。 


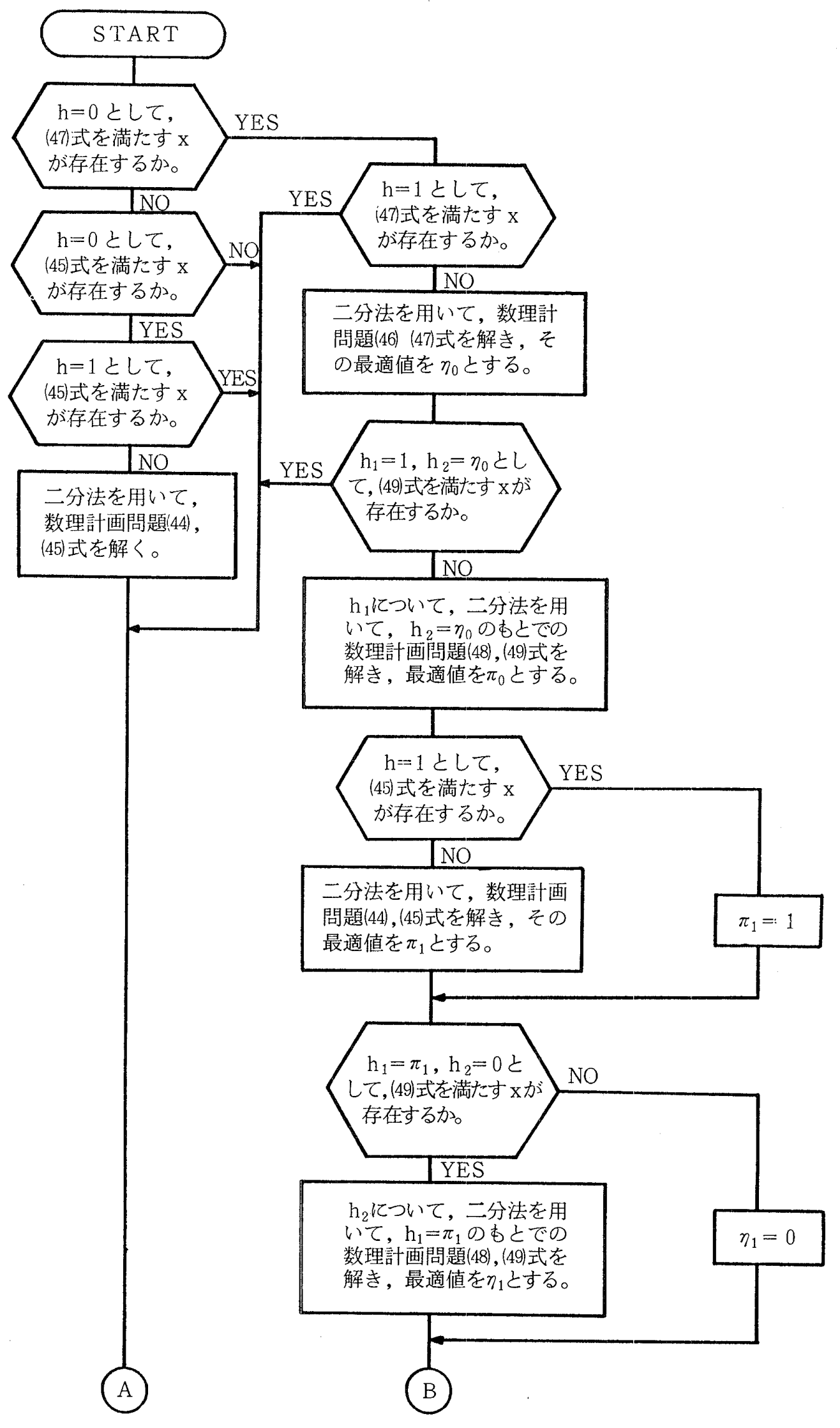

図 6 解法手順のフローチャート(1) 


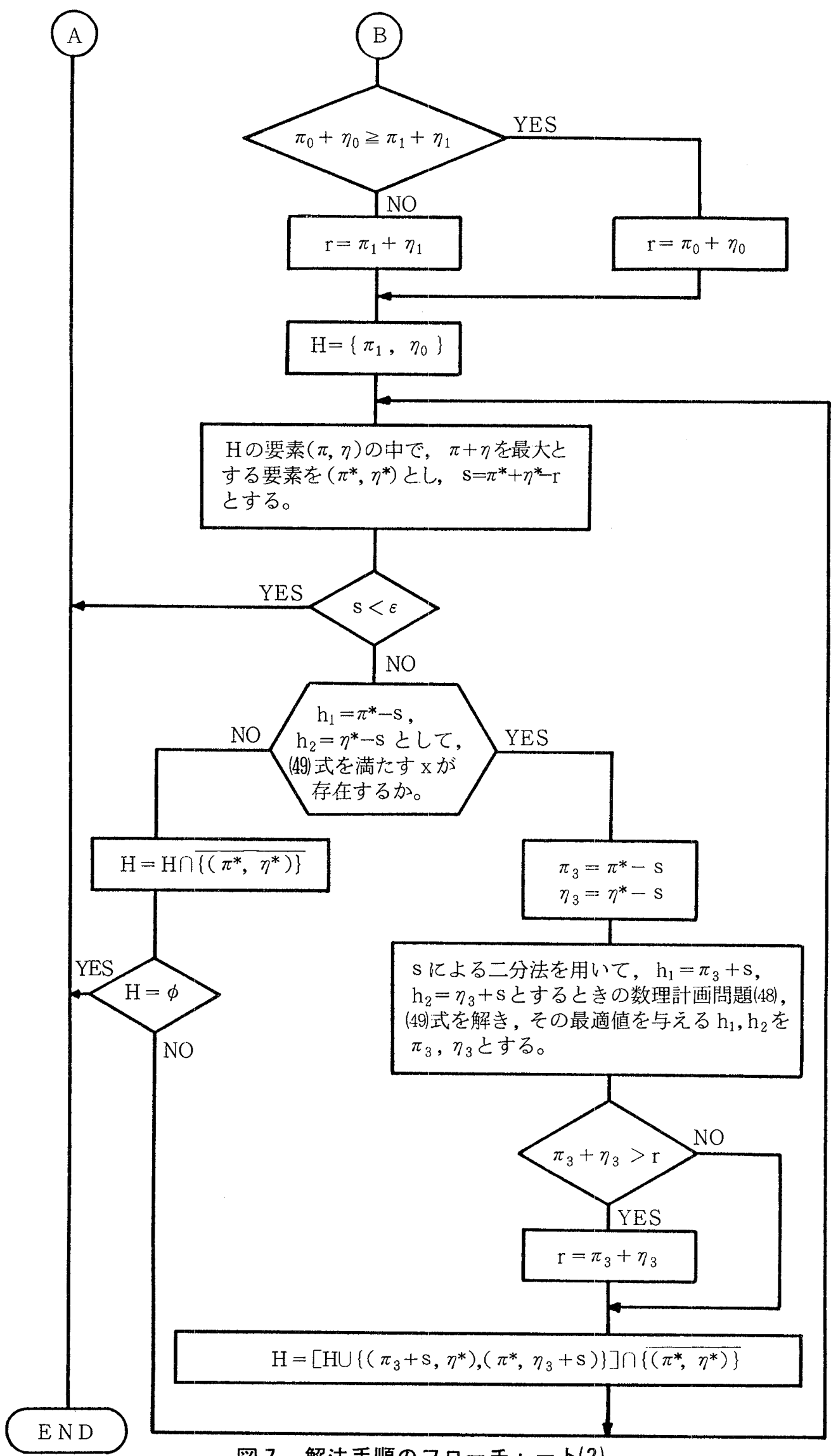

図 7 解法手順のフローチャート(2) 
この手順において，\&は許容範井を表わし，あらかじめ，意思決定者により与えられるすのとする。 また，記号 U，ク，一は，それぞれ，和集合，共通集合，補集合を表わす。

図 6 および図 7 に，乙の手順のフローチャートを示す。

手順22, 手順26亿おけるHの置き換えおよび，手順25における られるsは小さくなる。したがって，ての手順は有限回のステップで必ず終了する。

\section{3 数 值 例}

数値例として, 次の問題を考える。

(52)

$$
\left\{\begin{array}{l}
\tilde{y}_{1}=\widetilde{a}_{11} x_{1}+\tilde{a}_{12} x_{2} z-29 \\
\tilde{y}_{2}=\widetilde{a}_{21} x_{1}+\widetilde{a}_{22} x_{2} z-25 \\
\tilde{y}_{3}=\widetilde{a}_{31} x_{1}+\widetilde{a}_{32} x_{2} z 37
\end{array}\right.
$$

ここで, 各ファジィ係数 $\mathrm{a}_{\mathrm{ij}}$ は,

(53) $\tilde{\mathrm{a}}_{11}=(-3,2,2.5)_{\mathrm{L}_{1} \mathrm{~L}_{3}}$

(54) $\widetilde{\mathrm{a}}_{12}=(-9,3,3.5)_{\mathrm{L}_{1} \mathrm{~L}_{5}}$

(55) $\tilde{\mathrm{a}}_{21}=(-11,2.2,1.8)_{\mathrm{L}_{1} \mathrm{~L}_{2}}$

(56) $\quad \widetilde{\mathrm{a}}_{22}=(5,0.8,1)_{\mathrm{L}_{4} \mathrm{~L}_{1}}$

(57) $\tilde{a}_{31}=(6,2.1,2.1)_{L_{3} L_{5}}$

(58) $\tilde{a}_{32}=(5,1,1.2)_{\mathrm{L}_{1} \mathrm{I}_{3}}$

であり, reference 関数は,

(59) $\mathrm{L}_{1}(x)=\max [0,1-|x|]$

(60) $\mathrm{L}_{2}(x)=\max \left[0,1-|x|^{2}\right]$

(61) $\mathrm{L}_{3}(x)=\max \left[0,1-|x|^{\frac{1}{2}}\right]$

(62) $\mathrm{L}_{4}(x)=\max \left[0,1-|x|^{3}\right]$

(63) $\mathrm{L}_{5}(x)=\max \left[0,1-|x|^{\frac{1}{3}}\right]$

である，また，各ファジィ目標は次のように与えられる。

(64) $\mu_{1}\left(y_{1}\right)=\left\{\begin{array}{cl}0 & ; y_{1} \leqq-37 \\ 1-\left(\frac{y_{1}-29}{8}\right)^{\frac{1}{2}} & ;-37 \leqq y_{1} \leqq-29 \\ 1 & ;-29 \leqq y_{1}\end{array}\right.$

(65) $\mu_{2}\left(y_{2}\right)=\left\{\begin{array}{cl}0 & ; y_{2} \leqq-29 \\ 1+\frac{y_{2}+25}{4} & ;-29 \leqq y_{2} \leqq-25 \\ 1 & ;-25 \leqq y_{2}\end{array}\right.$ 
(66) $\quad \mu_{3}\left(y_{3}\right)=\left\{\begin{array}{cl}0 & ; y_{3} \leqq 31 \\ 1-\left(\frac{37-y_{3}}{6}\right)^{2} & ; 31 \leqq y_{3} \leqq 37 \\ 1 & ; 37 \leqq y_{3}\end{array}\right.$

乙の問題を 4.2 節の手順に従って解を求める。決定方式IVに基づく解は,

(67) $\left(x_{1}, x_{2}\right)=(3.41,2.37)$

となる。乙のとき， $\pi_{0}=0.603 ， \eta_{0}=0.192$ である。また，決定方式 I に基づく解は，

(68) $\left(x_{1}, x_{2}\right)=(3.75,2.16)$

となり， $\pi_{1}=0.702, \eta_{1}=0$ である。 $\pi_{0}+\eta_{0}>\pi_{1}+\eta_{1}$ であるから, 手順18において, $\pi_{2}=0.603, \eta_{2}$ $=0.192, r=0.795$ となる。 $\pi+\eta>r$ なる点 $(\pi, \eta)$ の領域は, 図 8 の三角形A B D 部分である。 手順19で， $\mathrm{H}=\{(0.702 ， 0.192)\}$ であるから，手順20で， $\pi^{*}=0.702 ， \eta^{*}=0.192 ， s=0.099$ となる。 つまり, 図 8 の線分 $\mathrm{AC}$ 上の点について，(49)式を満たす $x$ の存在を調べるととになる。C点まで調べ るのは, この点に扮いて, (49)式を満たす $x$ が存在しないととが判明すれば, 定理 1 の系より, 三角形 A B Dの部分の任意の点について，(49)式を満たす $x$ が存在しないととが示せるからである。手順22〜 手順 24 を行った結果 $\pi_{3}=0.637, \eta_{3}=0.126$ となった。つまり, 図 9 の点まで(49)式を満たす $x$ が存 在することがわかった。図 9 は, 図 8 の四角形 A B C Dの部分を拡大したすのである。 $\pi_{3}+\eta_{3} \leqq r$

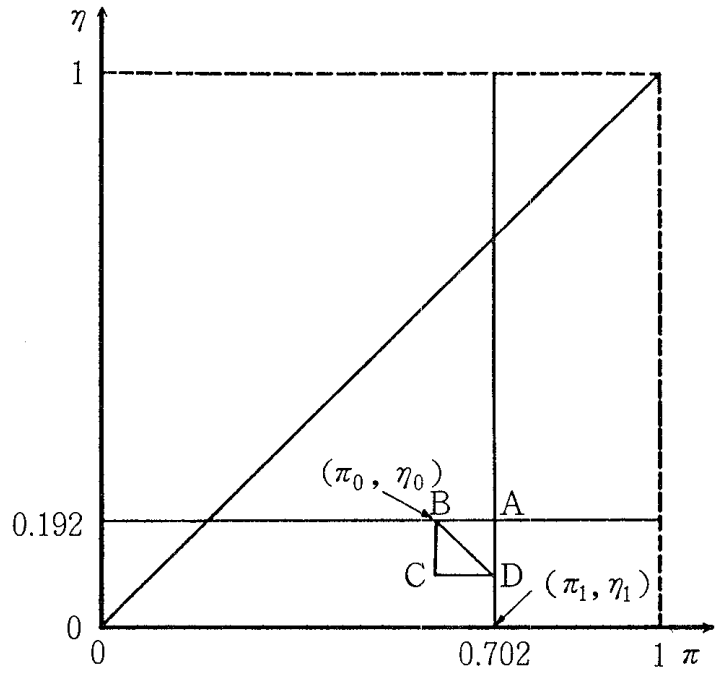

図 8 探索領域の説明

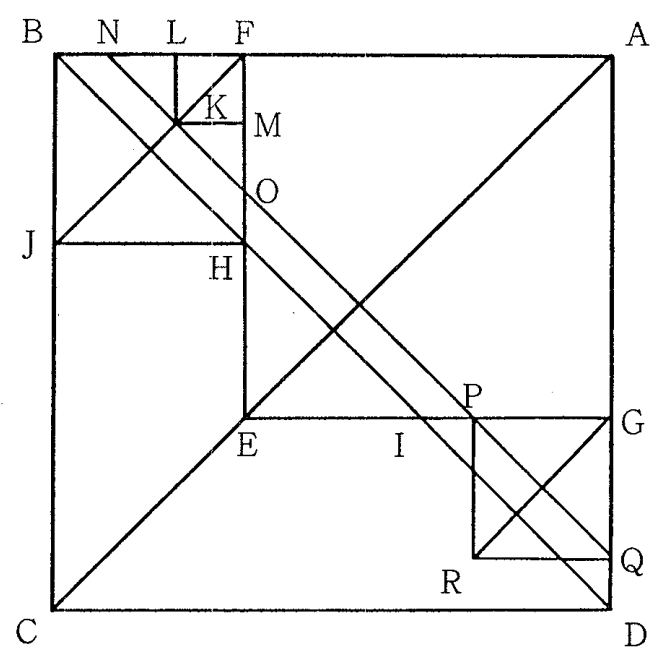

図 9 探索順序の説明

であるから, $r$ は変化せず $r=0.795$ である。このとき, $\pi+\eta>r$ なる点 $(\pi, \eta)$ の領域は, 図 9 の 三角形F B Hと三角形G I Dの部分となり, 四角形A F E Gの部分には，(49)式を満たす $x$ が存在しな いととになる。手順26で，Hは，H=\{(0.637，0.192)，(0.702，0.126)\}となり，手順20へ戻る。手

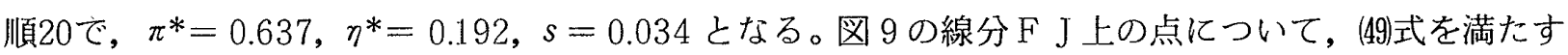

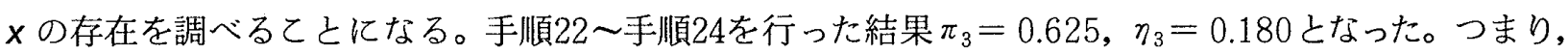

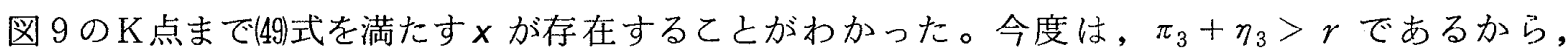


$r=0.804$ と変化し, $\pi+\eta>r$ なる点 $(\pi, \eta)$ の領域は, 図 9 の三角形 L N K と三角形MKO と三角 形 GPQの部分になる。手順26で, $\mathrm{H}=\{(0.625,0.192),(0.637,0.180),(0.702,0.126)\}$ とな り, 手順20へ戻る。手順20で, $\pi^{*}=0.702, \eta^{*}=0.126, s=0.024$ となり, 図 9 の線分 GR上の点に ついて，(49)式を満たす $x$ の存在を調べることになる。乙の場合，手順21で，点Rにおいて(49)式を満た す $x$ が存在しないととがわかり， $\mathrm{H}=\{(0.625 ， 0.192) ，(0.637,0.180) ，(0.678,0.102)\}$ となる。

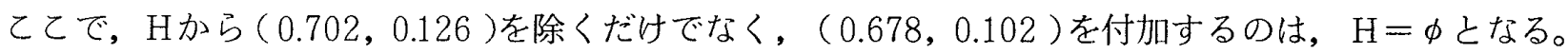
乙とを防ぐためである。乙のとき， $\pi+\eta>r$ なる点 $(\pi, \eta)$ の領域は，図 9 の三角形 L N K 之三角形 M K Oの部分になる。以下, 手順21で終了するまで続けると, 決定方式Vに基づく解は,

(69) $\left(x_{1}, x_{2}\right)=(3.43,2.39)$

となり, $\pi_{2}=0.624, \eta_{2}=0.182$ である。なお， とを $1.0 \times 10^{-6}$ として解いた。

\section{5. 結言}

本研究では, Pradeによる可能, 必然, 不可能, 偶然の 4 つの測度を基にして, てれらの相対的な 様相測度を定義し，その性質を明らかにした。また，種々の様相測度に基づく決定方式を分類し，意 思決定者の危険に対する態度との関係を論じた。さらに，てれらの決定方式をファジィ多目的線形計 画法へ応用し，その解法を示した。乙こで，定式化したファジィ多目的線形計画問題は，様相概念に 基づいて抢り，様相論的線形計画問題といえる。

ファジィ数理計画法は, 本研究で示したように, 決定方式に応じて, さまざまな解を得るととがで きる。したがって，意思決定者の主観を反映した解を見い出すてとができる。今後は，すでに提案さ れているファジィ数理計画法 [8] [9][10][11］［12］［13］に扔ける決定方式との関係の研究が 必要となるであろう。

\section{参考文献}

[1] Zadeh., L. A. : Fuzzy Sets as a Basis for a Theory of Possibility. Fuzzy Sets and System, 1, 1(1978), 3-28.

[2]菅野道夫：Fuzzy 測度と Fuzzy積分. 計測自動制御学会論文集, 8, 2(1972)，218-226.

[3] Prade, H. : Modal Semantics and Fuzzy Set Theory. Fuzzy Sets and Possibility Theory (ed. Yager, R. R. ), Pergamon Press, (1982), 232-246.

[4] 乾口雅弘, 市橋秀友, 田中英夫, 浅居喜代治: 可能性と必然性に基づくファジィ多目的線形計 画法.第 2 回ファジィシステムシンポジウム講演論文集， (1986)，172-178.

[5] 白井賢一郎：自然言語之様相論理. 数理科学, 275, 3(1986), 16-25.

[6] Dubois, D. and Prade, H. : Fuzzy Sets and Systems. Academic press, 1980.

[7] Bellman, R. and Zadeh, L. A. : Decision-making in a Fuzzy Enviroment. Management Science, 17, 4(1970), 141-164. 
[8] Tanaka, H. and Asai, K. : Fuzzy Linear Programming with Fuzzy Number. Fuzzy Sets and System, 13, 1(1984), 1-10.

[9] Orlovski, S. A. : Multiobjective Programming Problems with Fuzzy Parameters. Control and Cybernetics, 13, 3(1984), 175-183.

[10] Dubois, D. : Linear Programming with Fuzzy Data. The Analysis of Fuzzy Information (ed. Bezek, J. C. ), CRC Press, (1986).

[11] 矢野均, 坂和正敏：ファジィパラメータを含む多目的最適化問題に対する解の概念とその性質. Journal of Operations Research Society of Japan, 29, 1(1985), 21-42.

[12] 坂和正敏, 矢野均：ファジィパラメータを含む多目的非線形計画問題记対する対話型意思決定. 計測自動制御学会論文集，22，2(1986)，162-167.

[13] 坂和正敏, 矢野均：ファジィパラメータを含む多目的非線形計画問題に対する対話型ファジィ 満足化手法. 電子通信学会論文誌, J68-A，10(1985)，1038-1046.

連 絡 先： F591 堺市百舌鳥梅町 4丁804

大阪府立大学工学部経営工学科第 2 講座

乾 口雅弘

TEL $\quad 0722-52-1161$

EXT. 2374 


\title{
DECISION PROCEDURES BASED ON MODAL CONCEPT AND ITS APPLICATION TO FUZZY MULTI- OBJECTIVE LINEAR PROGRAMMING PROBLEM
}

\author{
Masahiro INUIGUCHI Hidetomo ICHIHASHI \\ Hideo TANAKA \\ University of Osaka Prefecture
}

The concepts of possibility distribution and measure have been introduced by L.A. Zadeh. The possibility distribution is regarded as a fuzzy restriction which acts as an elastic constraint on the values that may be assigned to a variable. The possibility measure of an event may be interpreted as the possibility degree of occurrence of the event under a possibility distribution. On the other hand, possibility, necessity, impossibility and contingency have been naturally extended to deal with fuzzy sets in the framework of Venn's diagram, using h-level sets by H. Prade. Zadeh's possibility theory is recovered in this approach. However, these modalities are considered as absolute indices. Namely, the fact that the possibility of an event is very large does not imply the reason that the possibility of opposite event is small. In this paper, the relative modalities are defined using Prade's modalities. The relative possibility is defined as the degree where the possibility of an event is larger than the possibility of opposite event. In the same way, the relative necessity, the relative impossibility and the relative contingency are defined. The relative necessity is not dual of the relative possibility but equal to the relative possibility. Therefore, the dual relative possibility is defined. And relations between the relative modalities and the absolute modalities are investigated. As one of the applications of these modalities, the decision procedures based on the modal. concept are considered and divided into eight classes, so that fuzzy multiobjective linear programming problems are formulated using these procedures. These problems are reduced to nonlinear programs which are not necessarily convex programs. An approximating method of the global optimal solution using simplex method is proposed. 